
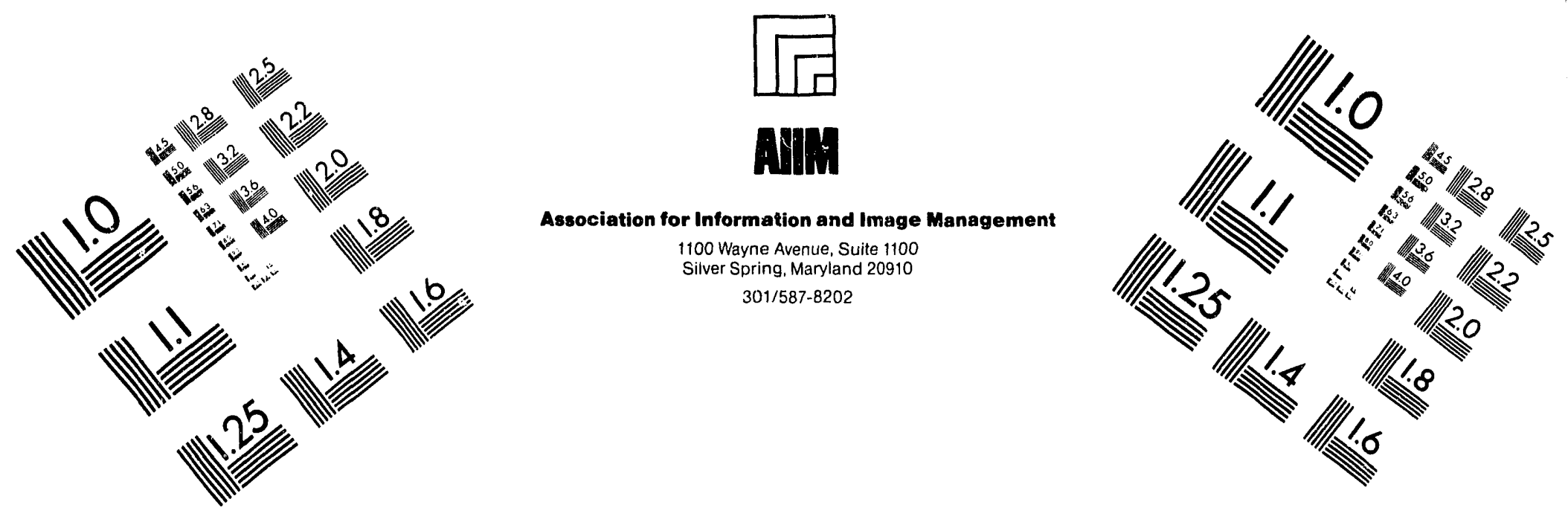

\title{
Centimeter
}

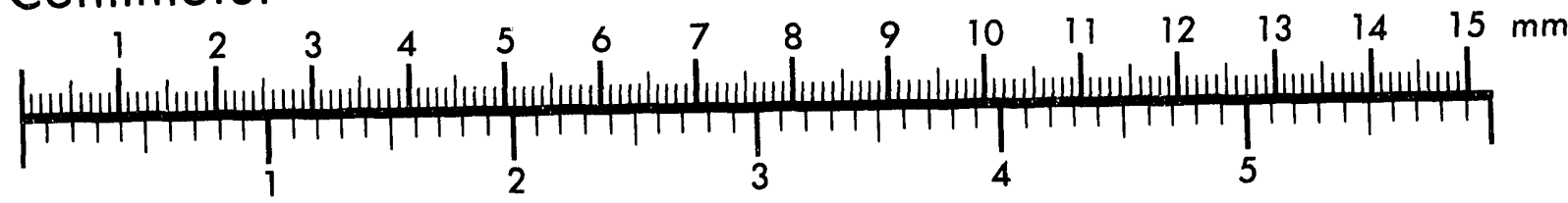
Inches
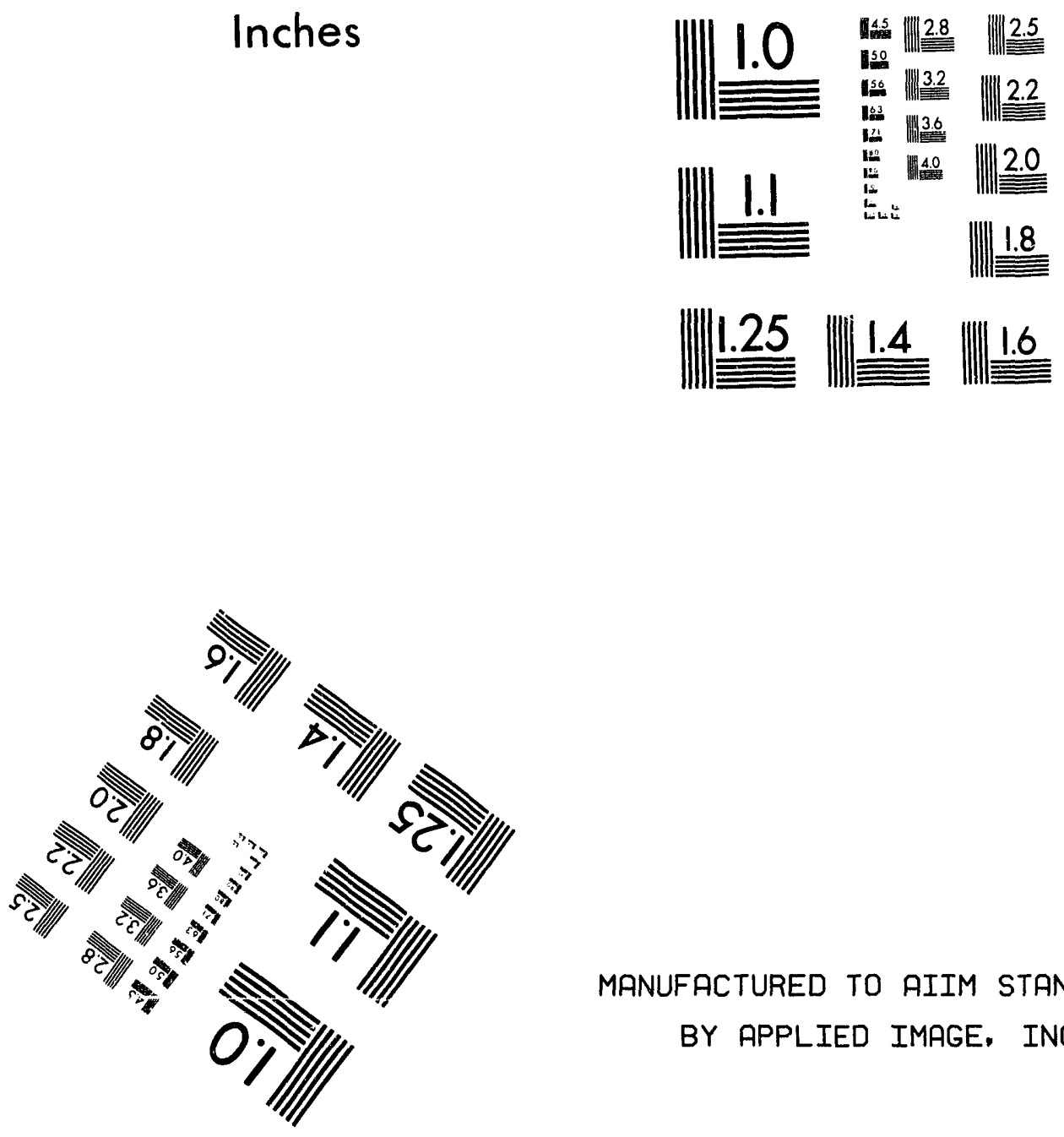

MANUFACTURED TO AIIM STANDARDS

BY APPLIED IMAGE, INC.

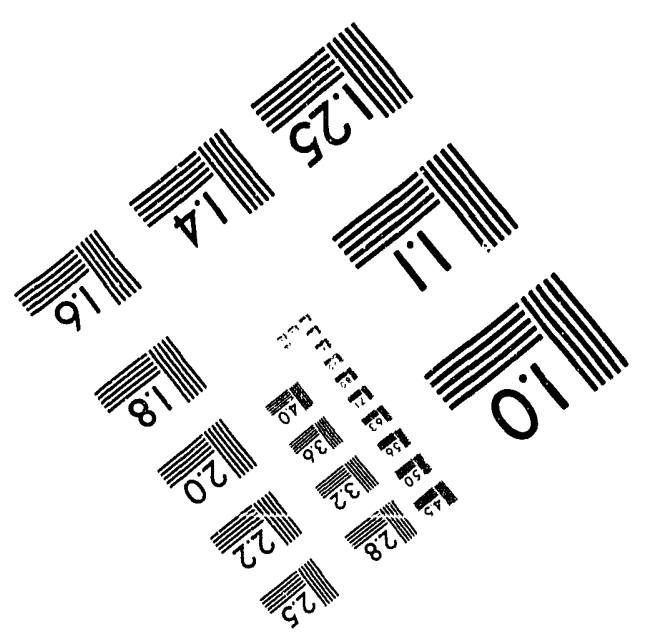



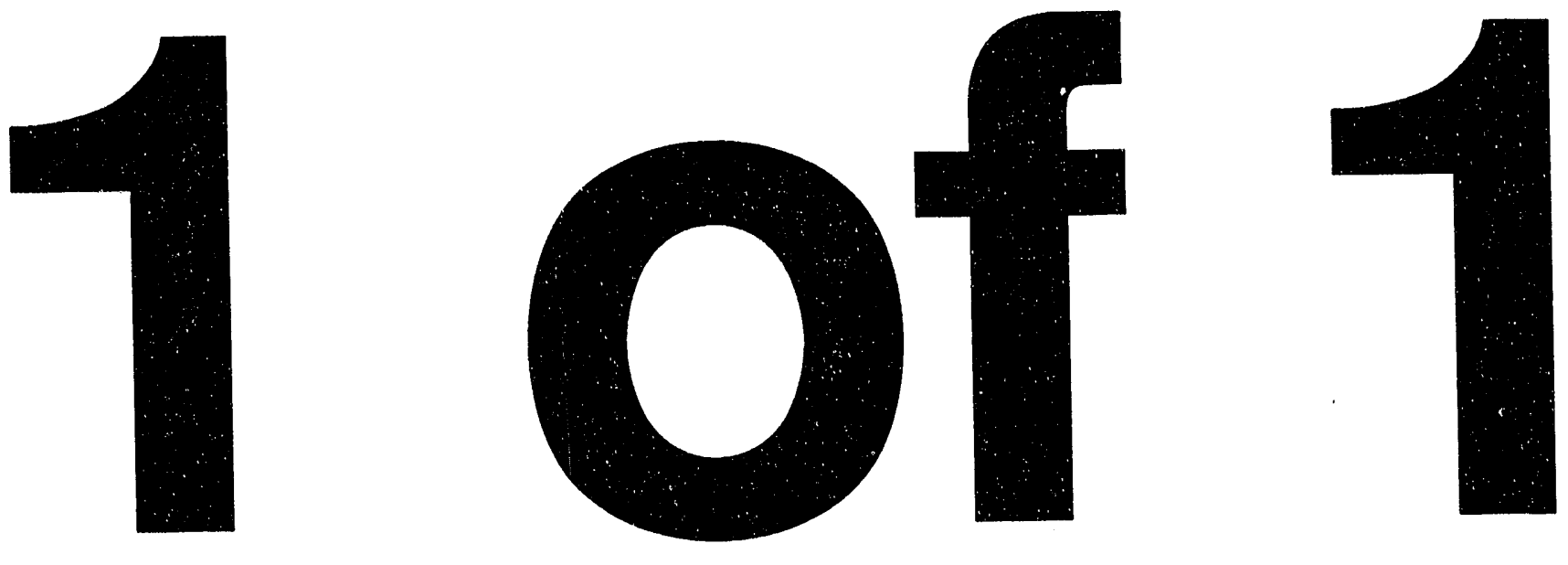


\section{$\frac{53.988 \delta(8)}{6.11 .938}$}

PPPL-2905

UC-420,426
PREPARED FOR THE U.S. DEPARTMENT OF ENERGY, UNDER CONTRACT DE-AC02-76-CHO-3073

PPPL-2905

EXPERIMENTAL EXPLORATION OF PROFILE CONTROL IN THE PRINCETON BETA EXPERIMENT-MODIFIED (PBX-M) TOKAMAK

BY

S. BERNABEI, R. BELL, M. CHANCE, ET AL.

MAY, 1993

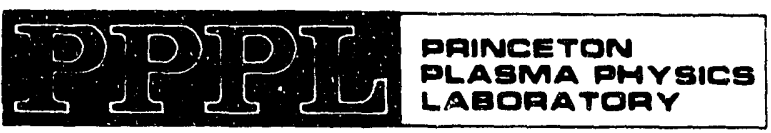

\section{plasma physics}

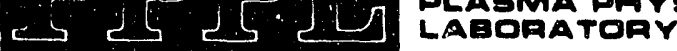

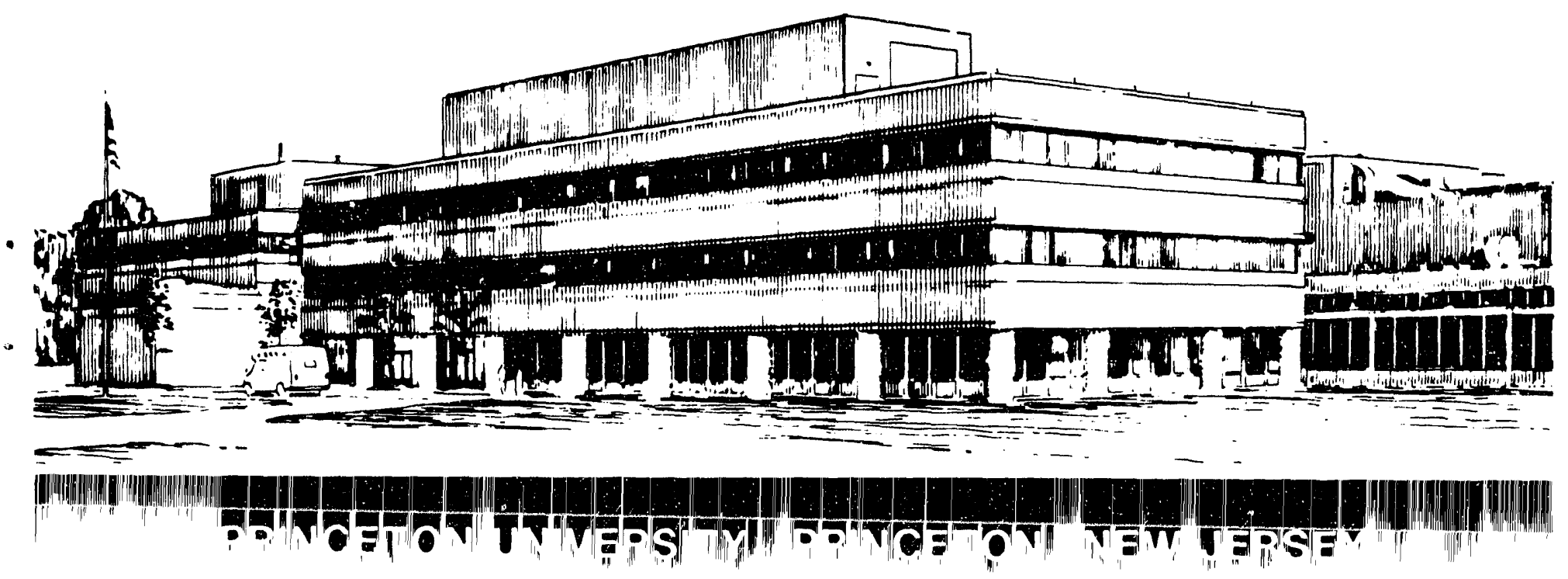




\section{NOTICE}

This report was prepared as an account of work sponsored by an agency of the United States Government. Neither the United States Government nor any agency thereof, nor any of their employees, makes any warranty, express or implied, or assumes any legal liability or responsibility for the accuracy, completeness, or usefulness of any information, apparatus, product, or process disclosed, or represents that its use would not infringe privately owned rights. Reference herein to any specific commercial produce, process, or service by trade name, trademark, manufacturer, or otherwise, does not necessarily constitute or imply its endorsement, recommendation, or favoring by the United States Government or any agency thereof. The views and opinions of authors expressed herein do not necessarily state or reflect those of the United States Government or any agency thereof.

\section{NOTICE}

This report has been reproduced from the best available copy.

Available in paper copy and microfiche.

Number of pages in this report: 35

DOE and DOE contractors can obtain copies of this report from:

Office of Scientific and Technical Information

P.O. Box 62

Oak Ridge, TN 37831 ;

(615) $576-8401$.

This report is publicly available from the:

National Technical Information Service

Department of Commerce

5285 Port Royal Road

Springfield, Virginia 22161

(703) $487-4650$ 


\section{Experimental exploration of profile control in the Princeton Beta Experiment-Modified (PBX-M) tokamak*}

S. Bernabei, R. Bell, M. Chance, T.K. Chu, M. Corneliussen, W. Davis,

G. Gettelfinger, T. Gibney, N. Greenough, R. Hatcher, H. Hermann, D. Ignat, S. Jardin, R. Kaita, S. Kaye, C. Kessel, T. Kozub, H. Kugel, L. Lagin, B. LeBlanc, J. Manickam, M. Okabayashi, H. Oliver, M. Ono, S. Paul, S. Preische, P. Roney, N. Sauthoff, S. Schweitzer, S. Sesnic, Y. Sun, H. Takahashi, W. Tighe, E. Valeo, S. von Goeler and K. Voss

Princeton University, Plasma Physics Laboratory, Forrestal Campus

P.O. Box 451, Princeton, NJ 08543

M. Mauel and G. Navratil

Columbia University, Department of Applied Physics, 206 SW Mudd Bldg,

New York, NY 10027

R. Cesario

EURATOM-ENEA sulla Fusione, CRE Frascati

- C.P. 65, 00044-Frascati, Rome, Italy

S. Batha and F. Levinton

Fusion Physics and Technology

3547 Voyager Street, Suite 104, Torrance, CA 90503-1673

F. Rimini

JET Joint Undertaking, Abingdon Oxfordshire, OX143EA, United Kingdom 
N. Asakura

Naka Fusiun Research Establishment, Japan Atomic Research Institute

JAERI Mukoyania, Naka-Machi, Naka-gun, Ibaraki-ken, JAPAN

S. Jones, J. Kesner, S. Luckhardt, F. Paoletti, P. Woskov, and A. Zolfaghari Massachusetts Institute of Technology

77 Massachusetts Avenue, Cambridge, MA 02139

T. Seki

National Institute for Fusion Science

Furo.cho, Chikusa-ku, Nagoya 464-01, JAPAN

J. Bell, J. Dunlap, A. England, D. Greenwood, J. Harris, G. Henkel, S. Hirshman, R. Isler, and D. Lee

Oak Ridge National Laboratory, Fusion Energy Division, P.O. Box 2009

Oak Ridge, TN $37831-8072$

L. Blush, R. Conn, R. Doerner, Y. Hirooka, R. Lehmer, L. Schmitz, G. Tynan University of California-Las Angeles, Department of Physics

Plasma Physics Laboratory, 405 Hilgard Avenue, Los Angeses, CA 90024-15

* Paper 4I1, Bull. Am. Phys. Soc. 37, 1437 (1992). 


\begin{abstract}
The experimental program of the Princeton Beta Experiment-Modified (PBX-M)

Tokamak [Physics Fluids B, 2, 1271 (1990)] is directed towards tailoring plasma profiles to achieve greater stability and confinement and to gain access to the second stability region. Modification of the current density profile has been achieved with lower hybrid current drive (LHCD), leading to a regime free of global magnetohydrodynamic modes, while raising the value of $q(0)$ above unity. The diffusion of the fast electrons produced by LHCD has been examined using two dimensional hard $x$-ray imaging. Ion Bernstein waves (IBW) have been used for ion heating: a preliminary analysis shows that ion heating was spatially localized and in agreement with theoretical calculations. Divertor biasing has modified the electric field inside the last closed surface, resulting in the formation of a transport barrier, which in turn has reduced the threshold power of Neutral Beam Injection (NBI) for H-mode transition by $25 \%$.
\end{abstract}

PACS numbers: $52.55 . \mathrm{Fa}+52.35 . \mathrm{Hr}$ 


\section{INTRODUCTION}

The achievement of higher plasma pressure is one of the key determining factors for the size and the econrmical attractiveness of commercial tokamak fusion reactors. ${ }^{1-3}$ Plasma pressure is represented by the combination of two $\beta$ values: the toroidal $\beta\left(\beta_{t}\right)$, or plasma pressure normalized to the confining toroidal field pressure, and the poloidal $\beta\left(\beta_{p}\right)$, or plasma pressure relative to the poloidal magnetic field pressure. The regime that features both high $\beta_{t}$ and high $\beta_{p}$ properties is theoretically known as the second stable regime. ${ }^{4,5} \mathrm{High}$ pressure operation with high $\beta_{t}$ and high $\beta_{\mathrm{p}}$ can make the fusion power output more economical, and also may provide a self-sustained steady state current drive source from high $\beta_{\mathrm{p}}$-produced bootstrap current. ${ }^{6}$ Furthermore, theoretical analyses have predicted that an improvement of previously known plasma instabilities may be achieved by self-stabilizing min-B effects in high $\beta_{\mathrm{p}}$ plasmas. 7,8

Second stability has been achieved, to date, only within limited plasma radial domains rather than throughout the full plasma volume. One of these domains is found near the magnetic axis on Doublet III-D (DIII-D) ${ }^{9}$ and Joint European Torus $(J E T)^{10}$ with non-monotonic $q(r)$ profiles. In both cases, the improved transport near the axis produced very high-pressure and high- $T_{\mathrm{i}}$ conditions. Access to the second stability regime in the outer plasma region was achieved in Princeton Beta Experiment-Modified (PBX-M) by imposing a large indentation in order to enhance the stability. ${ }^{11}$ In these experiments, the confinement improvement resulted in an increased figure of merit for high pressure, with a ratio of $\beta_{t}$ to $(\mathrm{V} / \mathrm{aB})$ of $3.5-4.0$ $(\% \cdot \mathrm{m} \cdot \mathrm{T} / \mathrm{MA})$ where $\mathrm{I}$ is the plasma current, $\mathrm{a}$ is the midplane half radius and $\mathrm{B}$ the toroidal magnetic field. The energy confinement time for these discharges was more than a factor of 3.5 times the ITER89-P scaling. ${ }^{12}$ Analysis of H-mode pressure profiles at the edge in Axi-Symmetric Divertor Experiment (ASDEX)13 suggest that the high pressure gradients at the plasma edge at the $\mathrm{H}$-mode onset are consistent with second stability.

$\mathrm{PBX}-\mathrm{M}^{11}$ is a medium sized tokamak with a major radius of $1.65 \mathrm{~m}$, a midplane 
halfwidth of $0.3 \mathrm{~m}$, and plasma height of $0.7 \mathrm{~m}$, and is equipped with high indentation capability. Five sets of passive conducting plates cover over $70 \%$ of the plasma surface and serve to stabilize surface kink modes. The plan of the PBX.M experiments is to systematically explore improvements in plasma stability and confinement leading to full-volume second stability, using techniques which control both current and pressure profiles, plasma shape, and edge electrostatic potential.

Theoretical Magnetohydrodynamics (MHD) analyses have indicated that the establishment of favorable $q(r)$ profiles, with particular sensitivity to $q(0)$, is essential for access to the second regime. The minimum $q(0)$ for the second regime depends on the magnetic shear $q(r)^{\prime}$, plasma pressure profile, and plasma shaping. ${ }^{5}$ In addition, it is important to control the parallel current component $\left(j_{\|}\right)$and alter the $q(r)$ profile in the off-axis domain, where the bootstrap current, which is related to the pressure gradient, may be dominant. In PBX-M, lower hybrid current drive (LHCD) has been chosen as the means to modify the parallel current profile.

An ion Bernstein wave (IBW) system has been chosen for pressure profile control, since off-axis ion heating should be achievable by varying the resonance location. Heating the bulk ions with IBW is more attractive than creating highly energetic ions as with ion cyclotron heating.

Electric field control at the plasma edge has been implemented by biasing the passive stabilizing plates. In PBX-M, the electrical biasing between outer-major-radius and inner-major-radius plates can produce a poloidallyasymmetric $m=1$ electric potential. Recent experimental results 14,15 and theoretical analyses 16 indicate that the sheared poloidal plasma flow produced by the edge potential may be the dominant factor in edge transport properties. The reduction of edge transport, and consequently, the decrease of ion and electron collisionality near the plasma edge, is important for placing the full plasma volume into the second stability regime.

PBX-M remains unique with its capability for strong indentation, which enhances MHD stability, and where the $q(0)$ required for the second stable regime is substantially lower than that required for the standard D-shaped configuration. 
It is important to determine the time evolution of the plasma current profile during a discharge to perform active profile control. A 2-dimensional hard x-ray imaging system has been developed specifically to monitor the radial location of current-carrying energetic electrons sustained by LHCD. The Motional Stark Effect (MSE) $\mathrm{q}$ diagnostic ${ }^{17}$ is a multi-channel system which measures the local magnetic field pitch-angle with $20 \mathrm{~ms}$ time resolution. A fast reciprocating Langmuir probe has been added to obtain measurements of the edge plasma properties and to provide information on edge transport.

In this paper, the initial results of the LHCD current modification, IBW pressure profile modification, and the effect of electric-potential biasing will be presented along with some profiles measured with these new diagnostics.

\section{CURRENT PROFUE MODIFICATION WITH LHCD}

In PBX-M, LHCD is unique with a fast response phase shifter which can adjust the phase of the launched LH wave during the discharge (response time $\approx 9 \mathrm{~ms}$ for $180^{\circ}$ shift, $20 \% \mathrm{~ms}$ ). A total power of $2 \mathrm{MW}$ is planned with two launchers, each equipped with 32 waveguides. The initial operation of the LHCD system has demonstrated current profile modifications with launched power under $400 \mathrm{~kW}$. The operating frequency, $4.6 \mathrm{GHz}$, is sufficient for driving current in high-density and high- $\beta_{p}$ discharges.

This section will first examine the effect MHD activity can have on the current driven by LH. Next, a discharge free of MHD is presented where a change in the current profile with LHCD is measured and modelled. Finally, an effective diffusion constant of the fast electrons for the MHD-free discharge is calculated using hard x-ray images with a suitable model.

\section{A. Effect of global MHD modes on the LHCD produced profile.}

LHCD through its change of the current profile can radically alter the MHD behavior of a plasma discharge. By changing the plasma parameters, especially the plasma density and LHCD power, one can either increase the sawteeth activity or 
suppress it, increase the $q=1$ radius or decrease it to the point that $q(0)$ becomes larger than 1. LHCD can excite various modes, e.g., $m=1 / n=1$ mode, locked global $n=1$ mode ending in a minor disruption, $m=3 / n=2$ mode, or stabilize these modes. Most of these experiments were carried out with neutral beam injection NBI.

Two systems have been employed to analyze the MHD activity during LHCD: a soft $\mathbf{x}$-ray array and a set of ten magnetic pick-up coils. The soft $x$-ray array contains 32 diodes; it is placed in the mid-plane with lines-of-sight covering the entire plasma cross section. The magnetic coils are positioned on the outside midplane around the torus.

In general, there were two situations in which the radius of the $q=1$ surface decreased, or the $q=1$ surface was eliminated from the plasma. In one case, the elimination of the sawtooth crash leads to a continuous mode, discussed in this section, and in the other case, to the Magnetically Quiescent Regime which will be discussed in the next section.

In the first case, immediately after the switching on of the LHCD, the sawteeth were suppressed. After approximatelly $100 \mathrm{~ms}$, the sawieeth would reappear, but then with an inversion radius which was smaller than the initial sawtooth radius by nearly a factor of two. The inversion radius would continue to decrease until the sawteeth were again suppressed. This decrease in the inversion radius is an indication of a similar decrease in the $q=1$ surface radius. The large decrease in the radius of the $q=1$ surface was corroborated by a change in the position of the $m=1 / n=1$ sawtooth precursor. The sawteeth would remain suppressed until the end of either NBI or LHCD.

Immediately after the first sawteeth suppression, an $n=2$ (mostly $3 / 2$ ) mode would begin to grow, resulting in an observable loss of fast electrons and a small loss in the hollowness of the hard $x$-ray image. This $n=2$ mode would continue for the duration of NBI. Without NBI, the $n=2$ mode would disappear and an $n=1$ mode would grow. This $\mathrm{n}=1$ mode would show a strong $\mathrm{m}=1$ component, producing a loss of central thermal electron energy with the central soft $x$-ray profile dropping by a factor of two. The hollowness of the hard $x$-ray profile would also be rapidly lost as the $x$-ray profile 
became quite peaked. It is clear that the onset of global $n=1$ mode is a major obstacle to the ability to control the current profile.

\section{B. Magnetically Quiescent Regime with off-axis RF power deposition.}

A discharge free of MHD has been produced for the entire duration ( $0.45 \mathrm{sec}$ ) of the $\mathrm{LH}$ pulse, which is longer than the magnetic diffusion time (of about $0.2 \mathrm{sec}$ ). It was obtained in a bean shaped plasma configuration, with a magnetic field $B_{T}=1.53 T$, a safety factor $q_{95}=7.5$, and the combined injection of lower hybrid and neutral beam power $\left(\mathrm{P}_{\mathrm{LH}} \sim 350 \mathrm{~kW}, \mathrm{n}_{\|}=2.1, \mathrm{P}_{\mathrm{NBI}} \sim 564 \mathrm{~kW}\right)$. The characteristics of this discharge are shown in Fig. 1. After the LH ramp-up and for the remainder of the LH pulse (0.4 s), a significant drop in the surface loop voltage $\left(V_{L}\right)$ was observec. A comparison with a similar neutral beam only discharge shows a relative drop in $\mathrm{V}_{\mathrm{L}}$ of up to $65 \%$ [Fig. $1(\mathrm{~d})]$.

The central soft $x$-ray trace shows the presence of sawteeth in the NBI reference shot, while $70 \mathrm{~ms}$ after the $\mathrm{LH}$ application sawteeth were suppressed in the $\mathrm{LH}+\mathrm{NBI}$ plasma. The presence of sawteeth activity can be clearly seen in the left part of the contour plot of the soft X-ray signal (Fig. 1f). While sawteeth were still present, their inversion radius and the location of the $m=1 / n=1$ precursor gradually moved inward, indicating a decrease of the $q=1$ radius. About $100 \mathrm{~ms}$ after the sawteeth suppression, the $m=1 / n=1$ mode vanished. The rate of shrinking of the inversion radius suggests that after a few tens of milliseconds $\mathrm{q}(0)$ should rise above 1 . This was measured by the Motional Stark Effect (MSE) diagnostic. During the remainder of the discharge, no local or global MHD activity was nbserved. The 2 Dimensional hard x-ray image (Fig. 2) shows an emission profile that was peaked off axis and this "hollow" profile was not affected by the presence of the local $m=1$ mode. This observation supports the hypothesis of an off-axis wave deposition with a consequent broadening of the current density profile.

During the long MHD quiescent period, the electron temperature and density profiles were peaked with the following central and line averaged values: $\mathrm{T}_{\mathrm{eo}} \sim 1.2$ $\mathrm{keV},\left\langle\mathrm{T}_{\mathrm{e}}\right\rangle-0.5 \mathrm{keV}, \mathrm{n}_{\mathrm{eo}} \sim 2.5 \times 10^{13} \mathrm{~cm}^{-3}$, and $\left\langle\mathrm{n}_{\mathrm{e}}>\sim 1.3 \times 10^{13} \mathrm{~cm}^{-3}\right.$. Visible 
bremsstrahlung measurements show a slight increase in Zeff, from 2.4 to 2.6 at $t=0.53$ sec; this is evidenced by the increase of the soft $x$-ray signal in the early part of the LHCD power application. The larger increase at the end of the pulse is yet to be explained.

The measured q-profiles from MSE are shown in Fig. 3 at $t=0.53 \mathrm{~s}$, during the MHD free period. They show an increase of the central $q$, and a consequent broadening of the current density profile during LH injection. This change was maintained for a time longer than the magnetic diffusion time, and it is consistent with the hard $x$-ray profile which remains peaked off-center for the total duration of the radio frequency (RF) pulse.

\section{TRANSP analysis of the MHD-free discharge}

The TRANSP data analysis code ${ }^{18}$ is a well-known tool that uses experimental data to determine the current, particle, and energy transport properties of plasma discharges. Specific inputs into the code include scalar discharge data $\left(I_{p}(t), V_{\text {lomp }}(t)\right.$, $B_{t}(t)$, etc.), the plasma outer boundary calculated as a function of time from a free-boundary equilibrium code, and kinetic profile data $\left[\mathrm{T}_{e}(r, t), \mathrm{n}_{\mathrm{e}}(\mathrm{r}, \mathrm{t}), \mathrm{T}_{\mathrm{i}}(\mathrm{r}, \mathrm{t})\right.$, $Z_{\text {eff }}(r, t), P_{\text {rad }}(r, t)$, etc.]. Fast ion information, determined from a Monte-Carlo calculation, has been benchmarked against measurements of fast neutral efflux escaping the plasma.

In order to model PBX-M discharges with LHCD, the Ignat/Valeo lower hybrid ray tracing and wave damping package, Lower Hybrid Simulation Code (LSC), 19 has been integrated into the TRANSP code. In a self-consistent fashion, the relevant experimental profiles are fed into LSC, which then tracks lower hybrid waves and employs the Karney/Fisch ${ }^{20}$ formalism to determine the wave absorption. Fundamental quantities calculated by LSC include the LH driven current and electron heating profiles. The LH driven current profile, along with other driven current profiles and an assumption about the plasma electrical resistivity, are input to the internal equilibrium solver, which consists of solving the poloidal magnetic field diffusion equation and the Grad-Shafranov equation. The assumption of Spitzer 
resistivity best characterizes the PBX-M plasmas. ${ }^{21}$ The $\mathrm{LH}$ electron beating profile is treated as an additional power source term in the electron power balance.

To determine how well the LH calculation and other assumptions model the discharge, a key comparison is made between the code calculations and the measurements from the Motional Stark Effect polarimetry diagnostic. As in Kaye et al., 21 it is the magnetic field pitch angle profile that is used for the comparison. Figure 4 shows the magnetic field pitch angle profiles as determined from TRANSP and from the MSE diagnostic. The absolute value of the pitch angle is shown. As can be seen, the calculation matches the trend in the measurement both in the interior of the plasma and farther out towards the edge. However, the TRANSP result is consistently higher than the MSE data near the center of the plasma, which means a more peaked current profile and a lower value of $q(0)(\sim 0.98$ in TRANSP).

\section{Fast electron transport}

Clearly an experiment aimed at controlling the current profile would be a failure at the start if the fast electrons generated by the waves diffused or were scattered across the radius before slowing down. In general, three mechanisms can be identified which can lead to a fast electron spatial distribution different from the one generated by the damping of the waves: a runaway condition, global MHD modes and radial diffusion due to some undetermined turbulence. Runaway conditions can be avoided by operation at sufficiently high density and by launching waves whose maximum phase velocity does not surpass the critical tail velocity. As was shown in the previous section, global MHD modes constitute a most dangerous obstacle to current profile control. With the absence of MHD modes, diffusion proves not to be a limiting factor. The task of this section is to determine the importance of diffusion for current profile control.

From hard $x$-ray images it can immediately be deduced that diffusion is low enough to maintain some fast electron localization by observing cases in which an off-center bremsstrahlung excission situation could be maintained for a time longer than the magnetic diffusion time. Quantitative evidence for the minor effect of 
diffusion comes from a calculation of the fast electron diffusion constant. The approach taken here is to assume a plausible physics model where the diffusion constant is a free parameter. A diffusion constant is guessed initially and the model fast electron density profile is calculated and compared to the experimental profile obtained from the hard x-ray image. The process is iterated, using different diffusion constants, until a good match is found. The remainder of this section provides a further description and results of this process.

The diffusion calculation model presented below solves the Fokker-Planck equation for the fast electrons. This time dependent equation is two dimensional in velocity space, one dimensional in real space, and includes the physics of lower hybrid acceleration (quasi-linear diffusion), ccilisional slowing down, pitch-angle scattering, electric field, and diffusion. Quasi-linear diffusion is incorporated in a response function form where the total effect is viewed as an integrated sum of many absorbed wave quanta. Solutions are computed using one or more discrete sources of absorbed quanta, i.e., the radial profile of the absorbed power for each quantum is assumed to be infinitely narrow.

This method of solution to the equation follows that described by Rax and Moreau, ${ }^{22}$ where the analytic solution is a sum over eigenfunctions of both ${ }^{-}$ radial-space and velocity-space operators. Once the full Fokker-Planck solution is obtained, the radial profile is easily computed.

The next step is to obtain the radial $x$-ray emissivity profile (and hence the fast electron radial profile) from the experimental image. Using the Stevens-von Goeler code, ${ }^{23}$ both the radial profile of the fast electrons and their velocity space distribution are assumed, and the corresponding $x$-ray camera image is computed and compared to the experimental image. Once a consistent match is found, the assumed radial profile is used as the experimental profile for subsequent comparison with results from the diffusion calculation.

The results presented here are from an analysis of the magnetically quiescent discharge, which was discussed in a previous section. Figure 5(a) shows the experimental fast electron current density profile obtained from the hard $x$-ray images 
using the Stevens-von Goeler code.

Figure 5(b) shows results from the diffusion calculation using three different values fo: the effective diffusion constant: the middle line gives a best fit with $D_{\text {eff }}=1.1$ $\mathrm{m}^{2} / \mathrm{sec}$, while the other two, which are a factor of two larger and smaller, give a noticeably poorer fit. To test the sensitivity of this result, other calculations were done for this discharge by varying the loop voltage, the lower hybrid absorption profile in velocity space, $Z_{\text {eff, }}$ and adding up to seven radially discrete sources to roughly model the effect of a broader radial absorption profile. In all cases, the best fit for the effective diffusion constant varied by less than about a factor of two. Within the context of the assumed models, an effective diffusion constant of $1.1 \mathrm{~m}^{2} / \mathrm{sec}$ is consistent with the steady state image of shot $\$ 298601$ to within a factor two. This value is comparable to the value of the one-fluid effective thermal diffusivity for this case.

There are many possible improvements to the modeling, including such effects as a time-varying electric field, a radially dependent diffusion constant, a momentum dependent diffusion constant, ${ }^{24}$ and radially varying collision frequency. On-going work includes analysis of other discharges and modeling of the time-dependent evolution of the two-dimensional images. Lastly, the diffusion calculation will be incorporated into a fully self-consistent LHCD ray-tracing and absorption model.

\section{ION BERNSTEIN WAVE ITEATING}

The Ion Bernstein Wave (IBW) heating system (4 MW at 40-80 $\mathrm{MHz}$ ) has been installed on PBX-M as a means of supplementing the existing 6 MW Neutral Beam Injection (NBI) heating for increasing the plasma beta and to control the pressure profile. For pressure profile control, the localized bulk ion heating of IBW is the primary tool. ${ }^{25}$ The ion energy transport is less anomalous than that of the electron energy so the IBW localized bulk ion heating should be suitable for pressure profile control. The location of the power deposition can be controlled by adjusting the ion cylotron harmonic absorption layer position. The experimental results also indicate, however, that pressure profile modification may be achieved by possible modifications to the core particle confinement by IBW. 
The IBW system presently consists of two antennas each connected to the Tokamak Fusion Test Reactor (TFTR) - Ion Cyclotron Range of Frequency (ICRF) 2 MW power, $40-80 \mathrm{MHz}$ transmitter. ${ }^{26}$ The IBW antenna elements are phased $(0-\pi)$ to reduce the low $n_{\|}$related edge losses, ${ }^{27}$ and the antennas are placed in the outer mid-plane region, which is the most favorable launching position for accessibility of $\mathrm{IBW}$ to the plasma core. ${ }^{25}$

Initial operation has been at the RF frequencies of 47 and $54 \mathrm{MHz}$. At $\mathrm{B}_{\mathrm{T}}=1.2 \mathrm{~T}$ and $1.4 \mathrm{~T}$, these frequencies correspond to the $5 \Omega_{\mathrm{D}}$ resonance near the plasma center. Higher frequency operation is generally desirable for reducing non-linear effects, and for launching faster waves to avoid excessive electron Landau damping (note that the launched $\lambda_{\|}=70-90 \mathrm{~cm}$ is fixed by the antenna geometry). Preliminary results for IBW up to $\approx 700 \mathrm{~kW}$ are presented here.

\section{A. Heating results.}

During the present run, IBW power up to $700 \mathrm{~kW}$ was applied to a plasma with a mixture of hydrogen and deuterium. Good comparison shots with and without IBW were taken for various IBW power levels. The stored energy showed a general increase comparable to NBI at similar powers. The temporal evolution of the stored energy showed a relatively rapid rise and fall, which was different from the plasma density behavior. Moreover, for the experimental parameter regimes used in the PBX-M, IBWH was in the saturated confinement regime, for which the stored energy is only weakly dependent on the plasma density. These observations indicate that the IBW was indeed depositing the power in the core of the plasma.

To investigate the feasibility of pressure profile control by localized ion heating, the time-resolved ion temperature profiles were measured with the eighteen channel charge-exchange recombination spectroscopy (CHERS) diagnostic, which used an impurity oxygen $\left(\mathrm{O}^{+7}\right)$ line excited by a deuterium neutral beam (the deposited NBI power was $\sim 700 \mathrm{~kW}$ ). In Fig. 6(a), the ion temperature profiles are shown with and without IBW (in this case the IBW power was $\sim 600 \mathrm{~kW}$ and the ohmic power $\sim 350$ $\mathrm{kW}$ ). The comparison shots were adjusted to have the same density profiles within the 
error bar, through appropriate gas programming. There was a significantly higher ion temperature with IBW $\left[\mathrm{T}_{\mathrm{i}}(0)=900-950 \mathrm{eV}\right.$ compared to $\mathrm{T}_{\mathrm{i}}(0)=600 \mathrm{eV}$ without]. The calculated power deposition for this case was $10-15 \mathrm{~cm}$ off the plasma center [dotted line in Fig. 6(a)] with the majority of the power going into the ions. Interestingly, the measured ion temperature profile in the case with IBW shows some change compared to the case without it. The ion temperature profile was consistently broader and a locally steeper $T_{i}$ gradient in the half-radius region was formed. The profile was consistent with the expected IBW power deposition profile. When the ion temperature rise was examined at an earlier time, the heating was found to occur first in the off-axis region (t $10 \mathrm{msec}$ after the RF power is fully turned on) with the central ion temperature increasing on a relatively slower time scale as the heat diffused toward the center, as shown in Fig. 6(b). The ion temperature profiles shown in Fig. 6(b) were obtained by averaging over two similar shots symmetrized over the plasma axis. This demonstration of the ion temperature profile broadening, as a result of the off-axis power deposition, is a very encouraging result for the eventual PBX-M pressure profile control by IBW.

The product of plasma density and the central ion temperature, which is a measure of ion stored energy, was found to increase linearly with IBW power up to the highest applied power. For the case of $600 \mathrm{~kW}$, the Thomson scattering (TVTS) showed a higher electron temperature $\left[\mathrm{T}_{\mathrm{e}}(0) \approx 750 \mathrm{eV}\right]$ compared to the case without IBW $\left[\mathrm{T}_{\mathrm{e}}(0)\right.$ $\approx 650 \mathrm{eV}$ ], measured at the same phase of the sawtooth cycle. This amount of electron temperature rise can be attributable to the higher ion temperature for the IBW case, since a relatively large amount of power is expected to flow from ions to electrons. Also, the IBW-heated ion temperature in this case was markedly higher than the electron temperature. Because of the similiarity of the electron density and temperature profiles with and without IBW, the NBI ion heating is expected to be comparable in both cases. This observation further supports the direct ion heating nature of IBW. The fusion neutron yield was also higher with IBW which can be explained by the higher electron temperature since most of the fusion neutrons were from beam-target reactions. 


\section{B. Particle confinement improvement}

It is well known that IBW can improve particle confinement as was demonstrated in Princeton Large Torus (PLT) ${ }^{28}$ and Alcator-C. ${ }^{29}$ In PBX-M, for some of the discharges, IBW has yielded very peaked density profiles which is a clear indication of particle transport changes in the plasma core region. This density peaking was also observed during the Japanese Institute of Plasma Physics Tokamak-II-Üpgrade (JIPPT-II-U) IBW experiment. ${ }^{30}$ The profile change in PBX-M took place relatively slowly over $150-200 \mathrm{msec}$. Initially, the density increased across the profile. However, the central density further increased in time, evolving toward a more peaked profile, as shown in Fig. 7(a) for a circular ohmic plasma. The mechanism for the peaked density profile formation is not fully understood at present. The central electron pressure doubled during IBW. With this density peaking, a complete elimination of sawteeth was also observed. Similar peaking of the density profile has been also observed with NBI(injected power $\sim 2 \mathrm{MW})+\mathrm{IBW}(\sim 500 \mathrm{~kW})$ heating [Fig. 7(b)]. With a relatively long IBW pulse, the profile steepened from the very flat, $\mathrm{H}$-mode-like profile in the early phase of the IBW application as shown. The central density reached $8 \times$ $10^{13} \mathrm{~cm}^{-3}$ which is not possible even with intense gas puffing. The density gradient reached $5 \times 10^{12} \mathrm{~cm}^{-4}$ in the core region $(r \approx 10-15 \mathrm{~cm})$. The central ion and electron temperatures ( $1.6 \mathrm{keV}$ and $1.1 \mathrm{keV}$, respectively) remained similar for the two cases. The IBW-induced peaked profile had higher central pressure, suggesting a possible improvement in the core confinement. The longer-term evolution of the density toward a peaked profile suggests that IBW may have been influencing the central plasma transport, either by enhancing the plasma inward pinch and/or reducing the particle diffusivity. This may be related to the poloidal velocity shear stabilization of turbulence by IBW, where the velocity shear layer may be created near the power absorption region. ${ }^{31}$ This type of study might lead to a possibility of particle transport control without the need for a central fueling source (e.g., neutral beams, pellets, etc. ) which would be highly desirable for a reactor. 


\section{Edge physics/ parametric instabilities}

To insure good heating efficiency and to reduce possible impurity generation, it is quite important to understand the edge physics occurring during IBW. This topic has been previously addressed by DIII-D experiments, ${ }^{32}$ in which significant heating of edge ions and electrous was reported. In the PBX-M IBW experiment, considerable progress has been made in understanding the IBW edge plasma interactions including plasma edge modification during IBW, the IBW antenna loading, and the conditions for parametric instability activity. Key to this effort were the measurements provided by the fast reciprocating edge probe. The measured edge density during IBW shows a strong reduction of the edge scrape-off density. This reduction of the density confirms the validity of the observed antenna loading based on the electron plasma wave excitation. ${ }^{33,34} \mathrm{~A}$ model using the ponderomotive force has shown good agreement with experimental observation. This reduced edge density appears to be reducing the antenna-plasma sheath effects during IBW. The probe measurements thus far have indicated no sign of edge electron heating or any significant change in the floating potential during IBW.

Associated with high power IBW, strong parametric instabilities were often observed during the DIII-D experiment which showed some correlation with the high energy ion tail and electron heating at the edge. Theoretical work, including convective loss and plasma gradient effects, shows that the edge density profile is critical for the parametric instability growth rate. According to the theory, the parametric activity should increase strongly if the plasma is moved away from the antenna (creating a wider low density "gap" region). To test this hypothesis on PBX-M, the plasma position was deliberately varied while monitoring the parametric activity. Under normal IBW operating conditions, very little parametric activity was observed ( $\leq 50 \mathrm{~d} B$ below pump). However, when the plasma edge was moved away from the IBW antenna by about 10 $\mathrm{cm}$, the parametric instability activity increased by $20-30 \mathrm{~dB}$. This result shows that parametric instabilities with IBW can be controlled by carefully controlling the distance between antenna and plasma. 


\section{IV. $m=1$ DIVERTOR BIASING EXPERIMENTS}

Edge plasma biasing affects the radial and poloidal electric field and the current distribution at the plasma boundary, which in turn can modify plasma transport. For the preliminary biasing experiments in PBX-M, the outboard divertor strike points in a double null configuration were biased with respect to the inboard strike points using elements of the passive plate assembly which surround the plasma. Bias voltages $-75 \mathrm{~V}$ $\leq \mathrm{V}_{\mathrm{b}} \leq 75 \mathrm{~V}$ were applied and bias currents $-300 \mathrm{~A} \leq \mathrm{I}_{\mathrm{b}} \leq 200 \mathrm{~A}$ wore observed. It was found that the threshold NBI power required for a transition to H-mode was lowered from 2.1 MW to 1.6 MW for $V_{b} \geq 25 V$ with $I_{b}=20-30 \mathrm{~A}$ (see Fig. 8). The required biasing power for this reduction in thrushold was quite small, less than $1 \mathrm{~kW}$.

In order to eliminate possible effects of wall conditioning on the $\mathrm{H}$-mode power threshold, the data presented in Fig. 8, was taken within a two hour period and the bias voltage was successively turned on and off in consecutive shots. At the end of the experimental run, the power threshold without biasing was found unchanged.

A fast reciprocating probe at the outboard mid-plane was used to measure the evolution of the edge radial profiles of the plasma density, electron temperature and floating potential. Low frequency density and potential fluctuations as well as the associated ExB radial plasma transport were measured simultaneously. It was observed that the plasma potential (peaking in the vicinity of the last closed flux surface) was increased at the outboard midplane (by a value corresponding to about one third of the applied biasing potential). As a result, the (negative) radial electric field was enhanced inside the last closed flux surface. Outside the last closed flux surface, the (positive) electric field was enhanced as well. The edge density gradient outside the separatrix increased by a factor of two. The fluctuation-induced transport was decreased by a factor of 3-4 across the entire edge region, possibly indicating the formation of a radial transport barrier at the outboard side of the plasma. Further differential biasing experiments at higher voltage, as well as, unipolar biasing experiments are planned. Divertor biasing will be investigated as an "helicity injector" in an effort to stabilize external kink modes with negative edge current. 


\section{SUMMMARY}

Progress has been made on the development of tools designed to control plasma profiles in the PBX-M tokamak. Initial results of $\mathrm{LH}$ current profile modification have shown the importance of MHD modes, but a magnetically quiescent regime in an indented configuration has been achieved by combining NBI and LH power. In this discharge, off-axis LH power deposition was maintained for a time longer than the magnetic diffusion time, resulting in $q(0) \geq 1$. Estimation of the fast-electron diffusion shows $\mathrm{D}=1.1 \mathrm{~m}^{2} / \mathrm{s}$.

Application of up to $700 \mathrm{~kW}$ of IBW power has shown the effectiveness of ion heating. Initial analysis shows that the heating was localized, at a plasma radius consistent with theoretical calculation: this result is encouraging for the IBW pressure profile concept. In general, a peaking of the electron density is observed.

Finally, divertor biasing has produced an enhanced electric field inside the last closed surface, resulting in the formation of a transport barrier: in this case, the NBI power needed for $\mathrm{H}$-mode transition was lowered by $25 \%$.

\section{ACKNOWLEDGMENT}

This work was supported by the U. S. Department of Energy, Contract No. DE-AC02-76CHO-3073. 


\section{REFERENCES}

1 J. F. Clarke, in Plasma Physics and Controlled Nuclear Fusion Research, Proceedings of 13th International Conference, Washington, D.C. (Oct. 1990), (International Atomic Energy Agency, Vienna, 1991), Vol. 3, p197.

2 Y. Seki, M. Kikuchi, T. Ando, Y. Ohara, S. Nishio, M.Seki, T. Takizuka, K. Tani, T. Ozeki, K. Koizumi, Y. Matsuda, M. Azumi, A. Oikawa, H. Madrame, T. Mizoguchi, F. Iida, Y. Ozawa, S. Mori, S. Yamazaki, T. Kobayashi, S. Hirata, J. Adachi, B. Ikeda, Y. Suzuki, N. Ueda, T. Kageyama, M. Yamada, M. Asahara, K. Konishi, N. Yokogawa, K. Shinya, A. Ozaki, H. Takaze, and S. Kobayashi, in Plasma Physics and Controlled Nuclear Fusion Research, Proceedings of 13th International Conference, Washington, D.C. (Oct. 1990), ( International Atomic Energy Agency, Vienna, 1991), vol. 3, p473.

3 R. W. Conn, F. Najmabadi, and the ARIES TEAM, in Plasma Physics and Controlled Nuclear Fusion Research, Proceedings of 13th International Conference, Washington, D.C. (Oct. 1990), ( International Atomic Energy Agency, Vienna, 1991), vol. 3, p670.

4 M. S. Chance, S. C. Jardin, and T. H. Stix, Phys. Rev. Lett., 51,1959 (1983).

5 J. J. Ramos, Phys. Rev. A, 42, 1021 (1990).

6 F. Najmabadi, R. Conn, and The ARIES team, in Plasma Physics and Controlled Nuclear Fusion Research, Proceedings of 14th International Conference, Wurzburg, Germany (Sep. 1992), (International Atomic Energy Agency, Vienna, 1993), IAEA-CN-56/G-1-1-1, to be published.

7 G. Rewoldt, W. M. Tang, and R. J. Hastie, Phys. Fluids, 30, p807, (1987).

8 W. M. ?nng, G. Rewoldt, R. L. Dewar, and M. S. Chance, Bull. Am Phys. Soc., 37, 1190, (1983). 
9 T. S.Taylor, T. H. Osborne, K. H. Burrell, T. N. Carlstrom, V. S. Chan, M. S. Chu, J. C. DeBoo, E. J. Doyle, C. M. Greenfield, R. J. Groebner, C. L. Hsieh, G. L. Jackson, R. James, L. L. Lao, E. A. Lazarus, S. I. Lippmann, T. W. Petrie, C. L. Rettig, H. St. John, D. P. Schissel, R. D. Stambaugh, E. J. Strait, A. D. Turnbull, W. P. West, J. Winter, D. Wroblewski, and the DIII-D Team, in Plasma Physics and Controlled Nuclear Fusion Research, Proceedings of 14 th International Conference, Wurzburg, Germany (Sep. 1992), ( International Atomic Energy Agency, Vienna, 1993), IAEA-CN-56/A-3-1 to be published.

10 JET-Team, in Plasma Physics and Controlled Nuclear Fusion Research, Proceedings of 13th International Conference, Washington, D.C. (Oct. 1990), (IAEA, Vienna, 1991), vol. 1, p27 and P. Smeulders, A. Edwards, G. Fishpool, T.C. Hender, M. Hugon, B. van Milligen, C. Nardone, G. Neill, L. Porte, S. Wolfe, and W. Zwingman in Plasma Physics and controlled Nuclear Fusion Research, Proceedings of 18th European Conference, Berlin, 1991, (European Physical Society, Geneva,1991), Vol. 2, p 53.

11 R. E. Bell, N. Asakura, S. Bernabei, M. S. Chance, P.-A. Duperrex, R. J. Fonck, G. M. Gammel, G. Greene, R. E. Hatcher, A. Holland, S. C. Jardin, T.-W. Jiang, R. Kaita, S. M. Kaye, C. E. Kessel, H. W. Kugel, B. LeBlanc, F. M. Levinton, M. Okabayashi, M. Ono, S. F. Paul, E. T. Powell, Y. Qin, D. W. Roberts, N. R. Sauthoff, S. Sesnic, and H. Takahashi, Phys. Fluids B, 2, 1271 (1990).

12P. N. Yushmanov, T. Takizuka, K. S. Riedel, O. J. W. F. Kardaun, J. G. Cordey, S. M. Kaye, and D. E. Post, Nucl. Fusion 30, 1999 (1990). 13 O. Gruber, G. Becker, G. von Gierke, K. Grassie, O. Kluber, M. Kornherr, K. Lackner, J.K. Lee, H. P. Zehrfeld, H. S. Bosch, H. Brocken, A. Eberhagen, G. Fussmann, O. Gehre, J. Gernhardt, E. Glock, G. Haas, J. Hofmann, A. Izvozchikov, G. Janeschitz, F. Karger, M. Kaufmann, M. Keilhacker, M. Lenoci, G. Lisitano, F. Mast, H. M. Mayer, K. McCormick, D. Meisel, V. Mertens, E.R. Muller, H. Murmann, H. Niedermeyer, W. Poschenrieder, H. Rapp, H. Riedler, H. 
Röhr, J. Roth, F. Ryter, F. Schneider, C. Setzensack, G. Siller, P. Smeulders, F.X. Söldner, E. Speth, K.-H. Steuer, O. Vollmer, F. Wagner, and D. Zasche, in Plasma Physics and Controlled Nuclear Fusion Research, Proceedings of 11th International Conference, Kyoto, Japan, 1986, ( International Atomic Energy Agency, Vienna, 1987), Vol. 1, p357.

14 T. Shoji, H. Aikawa, B.M. Annaratone, Y. Asahi, N. Asakura, G. Fuchs, K. Hoshino, A. W. Hyatt, K. Ida, S. Kasai, T. Kawakami, H. Kawashima, A. W. Leonard, H. Maeda, M. Maeno, T. Matsuda, Y. Miura, M. Mori, K. Odajima, H. Ogawa, T. Ogawa, S. Ohdachi, N. Ohyabu, S. Oikawa, E.K. Sanada, T. Seike, T. Shiina, M. Shimada, K. Shimano, H. Tamai, H. Toyama, S. Tsuji, K. Uehara, T. Yamauchi, K. Hasegawa, A. Honda, Y. Kashiwa, K. Kikuchi, M. Komata, F. Okano, M. Saito, E. Sato, N. Seki, T. Shibata, N. Suzuki, S. Suzuki, T. Tani, T. Tokutake, Y. Tomiyama, and T. Yamazato, in Plasma Physics and Controlled Nuclear Fusion Research, Proceedings of 14th International Conference, Wurzburg, Germany (Sep. 1992), ( International Atomic Energy Agency, Vienna, 1993), IAEA-CN-56/A-5-5, to be published.

15 R. J. Groebner, K. H. Burrell, P. Gohil, J. Kim, and R. P. Seraydarian in Plasma Physics and controlled Nuclear Fusion Research, Proceedings of 18th European Conference, Innsbruck, Austria, 1992, (European Physical Society, Geneva,1991), vol. I, p. 183.

16 H. Biglari , P. H. Diamond and P. W. Terry, Phys. Fluids B 2 (1), 1 (1990).

17 F. Levinton, R.J. Fonck, G.M. Gammel, R. Kaita, H.W. Kugel, E.T. Powell, and D.W. Roberts, Phys. Rev. Lett., 63, 2060 (1989).

18 R. J. Hawryluk, in proceedings of 1979 Workshop on Physics of Plasmas in Thermonuclear Regimes, Varenna Italy 1979, edited by B. Coppi and W. Sadowski (U.S. Department of Energy, 1981), p. 171.

19 D. W. Ignat, S. C. Jardin, E. J. Valeo and S. Bernabei, Bull. Am. Phys. Soc. 37 1499 (1992). 
20 C. F. F. Karney and N. Fisch, Phys. Fluids, 29, 180 (1986).

21 S. M. Kaye, F. M. Levinton, R. Hatcher, R. Kaita, C. Kessel, B. LeBlanc, D. C. McCune, and S. Paul, Phys. Fluids, 4, 651, (1992).

22 J.M.Rax and D. Moreau, Nucl. Fusion, 29, 1751 (1989).

23 S. von Goeler, N. Asakura, R. Bell, S. Bernabei, M. Chance, T. K. Chu, J. Dunlap, A. England, H. Fishman, G. Gettelfinger, N. Greenough, J. Harris, R. Hatcher, H. Herrman, D. Ignat, R. Isler, S. Jardin, S. Jones, R. Kaita, S. Kaye, J. Kesner, H. Kugel, B. LeBlanc, S. Luckhardt, F. Levinton, J. Manickam, M. Okabayashi, M. Ono, S. Paul, S. Preische, P. Roney, N. Sauthoff, T. Seki, S. Sesnic, J. Stevens, H. Takahashi, E. Valeo, and K. Voss, in Plasma Physics and controlled Nuclear Fusion Research, Proceedings of 18th European Conference, Innsbruck, Austria, 1992, (European Physical Society, Geneva,1991), Vol. II, pp 949-952.

24 H. E. Mynick and J. D. Strachan, Phys. Fluids 24, 695 (1981).

25 M. Ono, Phys. Fluids B 5, 241 (1993).

26 J. R. Wilson, in proceedings of 12 th conference on Plasma Physics and Controlled Nuclear Fusion Research (International Atomic Energy Agency, Nice, 1988), paper IAEA-CN-50/E4-1.

27 M. Ono, in proceedings of Ninth Topical Conference on Radio-Frequency Power in Plasmas (Charleston, 1991), American Institute of Physics - AIP Conference Proceedings 244 (New York, 1992), p223.

28 M. Ono, P. Beiersdorfer, R. Bell, S. Bernabei, A. Cavallo, A. Chmyga, S. Cohen, P. Colestock, G. Gammel, G. J. Greene, J. Hosea, R. Kaita, I. Lehrman, G. Mazzitelli, E. Mazzucato, D. McNeill, K. Sato, J. Stevens, J. Timberlake, J.R. Wilson, and A. Wouters, Phys. Rev. Lett., 60, 294 (1988).

29 J. D. Moody, M. Pokolab, C.L. Fiore, F.S. McDermott, Y. Takase, J. Terry, and S. M. Wolfe, Phys. Rev. Lett., 60, 298 (1988).

30 T. Seki, K. Kawahata, M. Ono, K. Ida, R. Kumazawa, T. Watari, F. Shimbo, A. Ando, K. Sato, Y. Yasaka, K. Adati, R. Akiyama, Y. Hamada, S. Hidekuma, S. 
Hirokura, O. Kaneko, A. Karita, T. Kawamoto, Y. Kawasumi, Y. Kitoh, M.

Kojima, T. Kuroda, K. Masai, S. Morita, K. Narihara, Y. Ogawa, K. Ohkuba, Y.

Oka, S. Okajima, T. Ozaki, M. Sakamoto, M. Sasao, K.N. Sato, H. Takahashi, Y.

Taniguchi, K. Toi, and T. Tsuzuki, in proceedings of Ninth Topical Conference on

Radio-Frequency Power in Plasmas (Charleston, 1991), American Institute of

Physics - AIP Conference Proceedings 244 (New York, 1992), p138.

$31 \mathrm{H}$. Biglari, M. Ono, P. H. Diamond, G. G. Craddock, in proceedings of Ninth

Topical Conference on Radio-Frequency Power in Plasmas (Charleston, 1991),

American Institute of Physics - AIP Conference Proceedings 244 (New York, 1992),

p. 376.

32 R.I. Pinsker, M.J. Mayberry, M. Porkolab, S. C. Chiu, and R. Prater, in proceedings of Ninth Topical Conference on Radio-Frequency Power in Plasmas (Charleston, 1991), American Institute of Physics -AIP Conference Proceedings 244 (New York, 1992), p169.

33 T.W. Jiang, G. Greene, M. Ono, N. Asakura, R. Bell, S. Bernabei, G. Gammel, R. Hatcher, A. Holland, R. Kaita, S.M. Kaye, H. Kugel, B. LeBlanc, F. Levinton, E. Lo, M. Okabayashi, S.F. Paul, N. Sauthoff, S. Sesnic, H. Takahashi, and J.

Timberlake, in proceedings of Ninth Topical Conference on Radio-Frequency Power in Plasmas (Charleston, 1991), American Institute of Physics - AIP Conference Proceedings 244 (New York, 1992), p129.

34 S. C. Chiu, M.J. Mayberry, R.I. Pinsker, C. C. Petty, and M.Porkolab, in proceedings of Ninth Topical Conference on Radio-Frequency Power in Plasmas (Charleston, 1991), American Institute of Physics - AIP Conference Proceedings 244 (New York, 1992), p169. 


\section{FIGURE CAPTIONS}

FIG. I The Magnetically Quiescent Discharge. (a) Neutral beam power.

(b) Lower Hybrid power. (c) Volume averaged density $\left(\mathrm{cm}^{-3}\right)$ for the discharge discussed (\#298601 with $\mathrm{LH}+\mathrm{NB}{ }^{\prime}$ ) and a similar discharge (\#298602 with NBI only). (d) Loop voltage. (e) Central soft x-rays. (f) Contour plot of the MHD activity in the central portion of the LH + NBI plasma, obtained from the soft $x$-ray diagnostic: no $x$-ray data was acquired before $240 \mathrm{msec}$.

FIG. \& Time evolution of the intensity of hard X-rays along a vertical chord through the magnetic axis for shot $\$ 298601$.

FIG. 3 Comparison of the q-profiles between NBI discharges with and without L.HCD, obtained with the MSE diagnostic.

FIG. 4 Magnetic field pitch angle profiles, as measu ed by MSE (asterisks) and as determined from TRANSP (solid line).

FIG. 5 Fast electron diffusion. (a) Fast electron current density profile obtained from an experimental x-ray image using the Stevens-von Goeler code. (b) Fast electron current density profile obtained from a theoretical calculation using three different diffusion constants. The units are $\mathrm{m}^{2} / \mathrm{sec}$. A loop voltage of $0.4 \mathrm{~V}$ is assumed.

FIG. 6 Ion Bernstein wave ion heating. (a) Ion temperature profiles with (solid circles) and without (open circles) IBW heating. Dotted line is the calculated power deposition with the resonance at $5 \Omega_{D}$. (b) Incremental ion temperature profiles at three times during application of IBW: open squares are data taken at time $t$, just prior to the observatioñ of IBW effects, solid 
circles are at $t=10 \mathrm{~ms}$, and solid squar os are $t=50 \mathrm{~ms}$ after the $R F$ power is fully on.

FIG. 7 Peaked density profiles with IBW. ip) Density profiles with and without IBW injected into a circular ohmic plasma. (b) In a strongly NBI heated bean-shaped plasma, a peaked density profile evolves during the late phase of IBW injection from a flat $\mathrm{H}$-mode-like density profile.

FIG. 8 NBI power threshold lowered with the application of an edge biasing voltage $\geq 25$ volts. Open symbols correspond to L-mode discharges, solid symbols correspond to $\mathrm{H}$-mode discharges. 


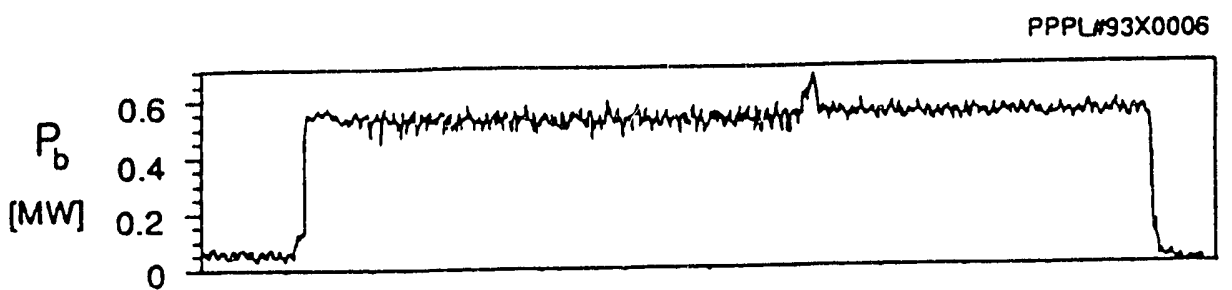

(a)

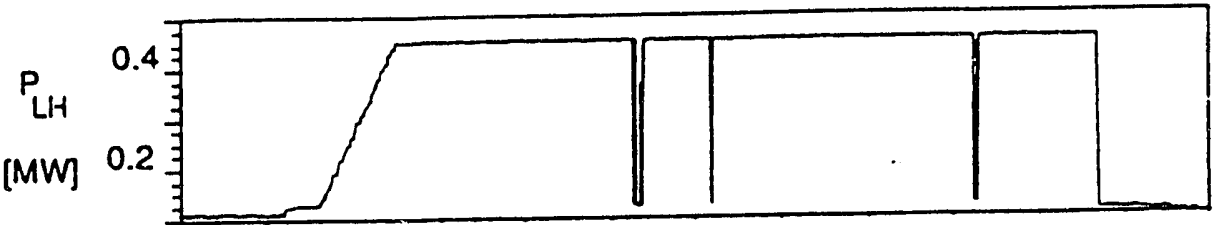

(b)

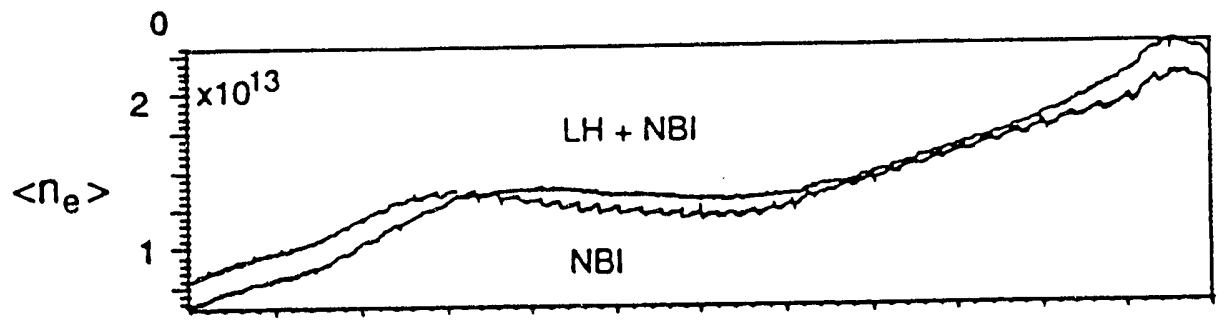

(c)

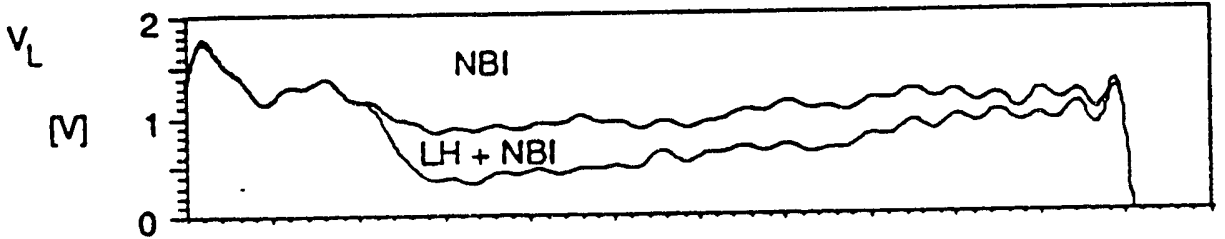

(d)

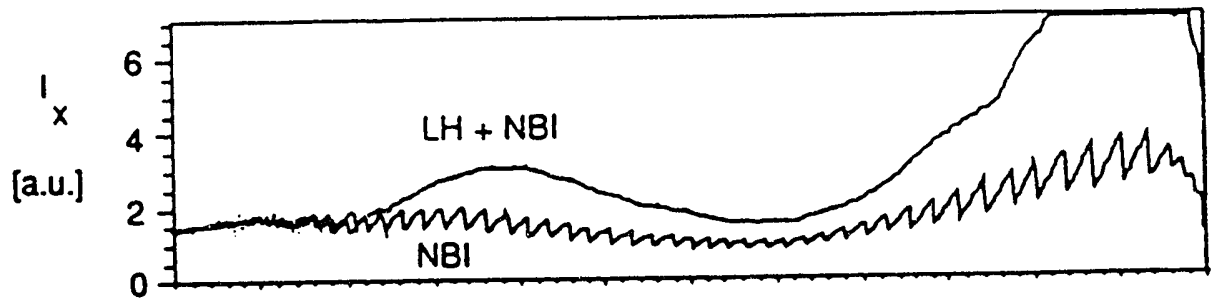

(e)

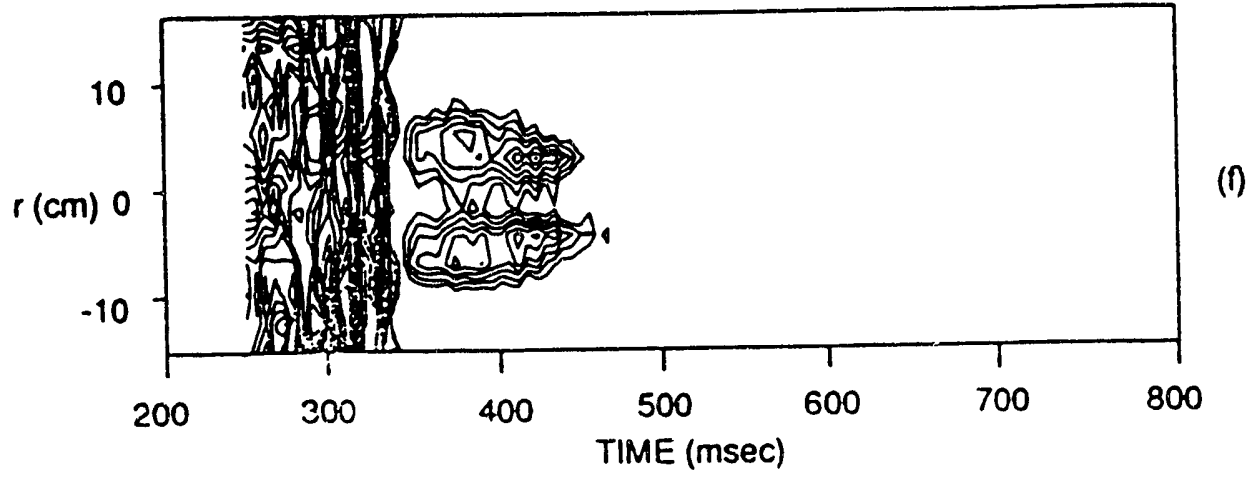

Fig. 1 
27

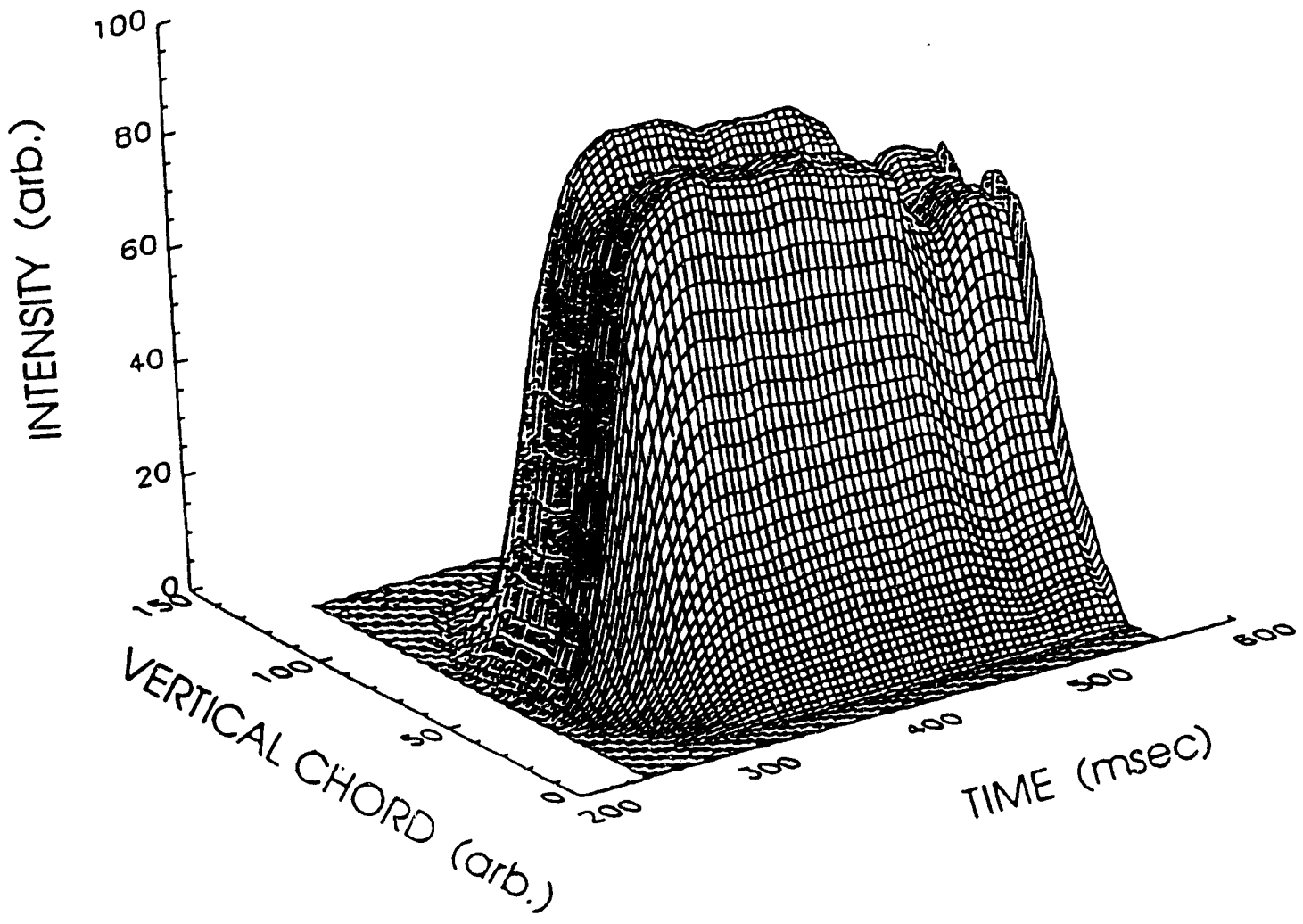

Fig. 2 


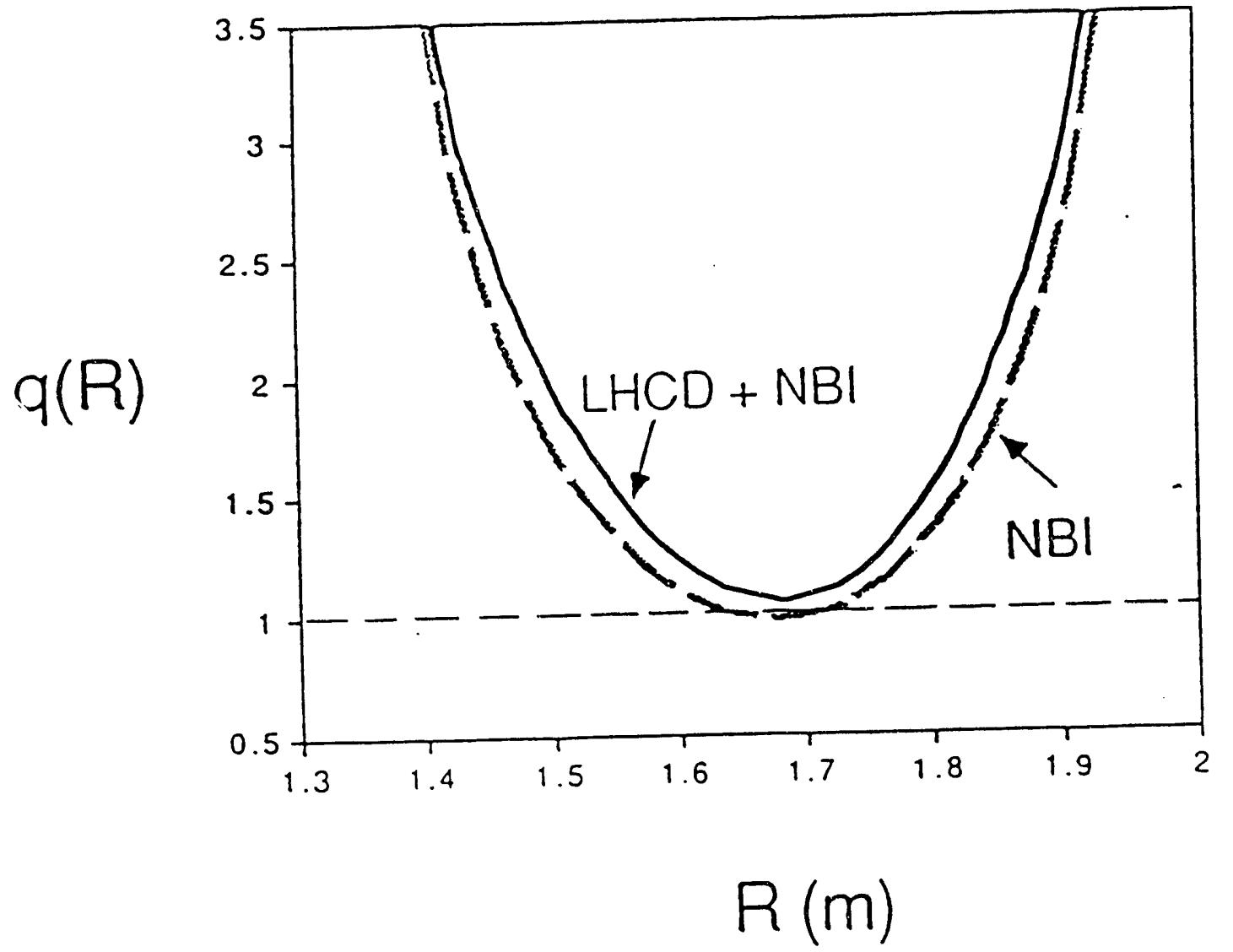

Fig. 3 


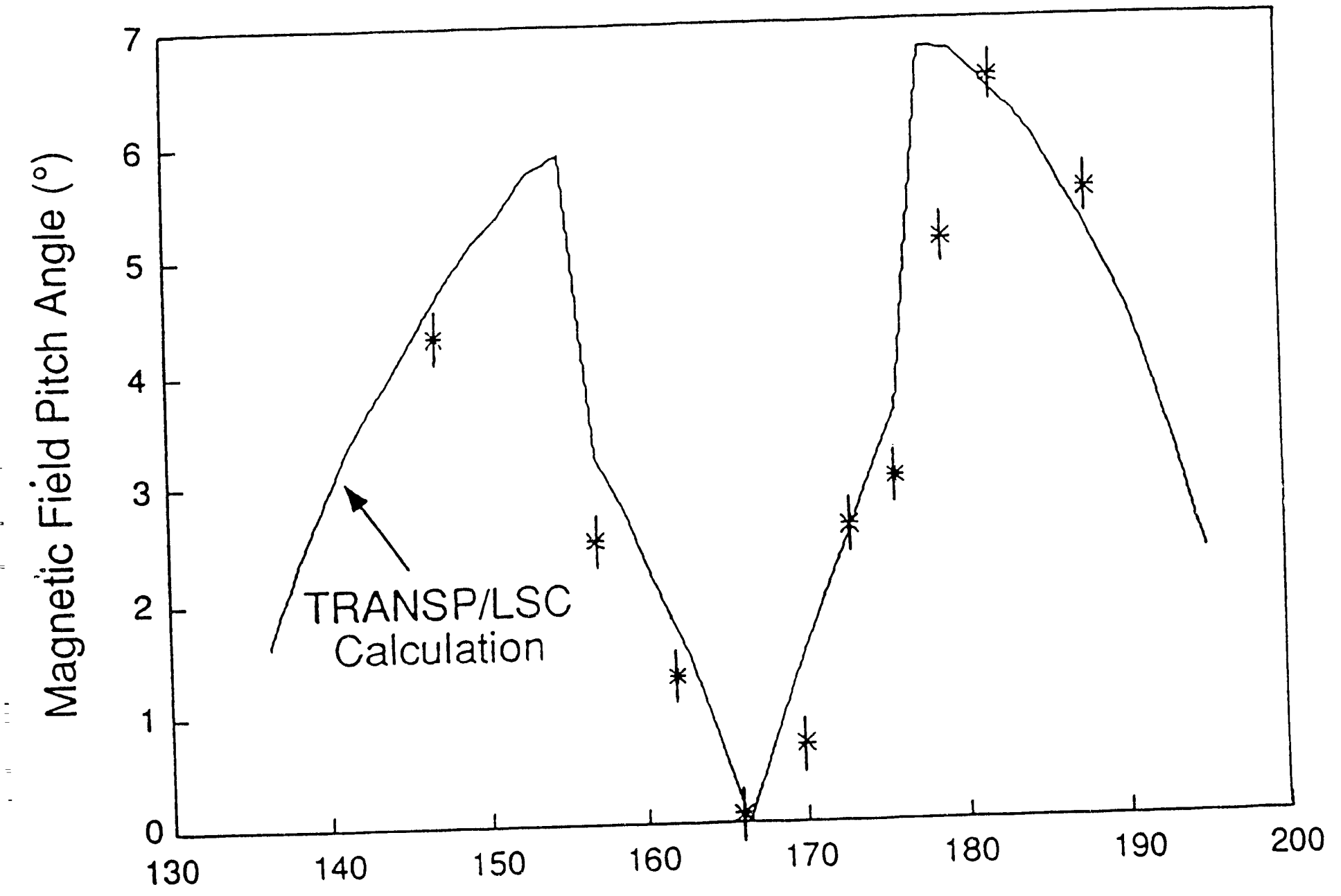

Major Radius (cm)

Fig. 4 


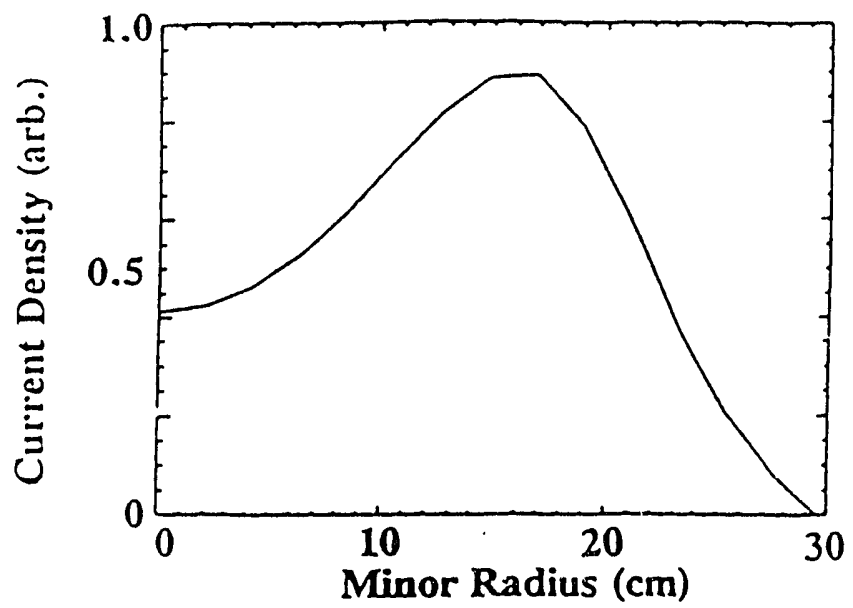

a)

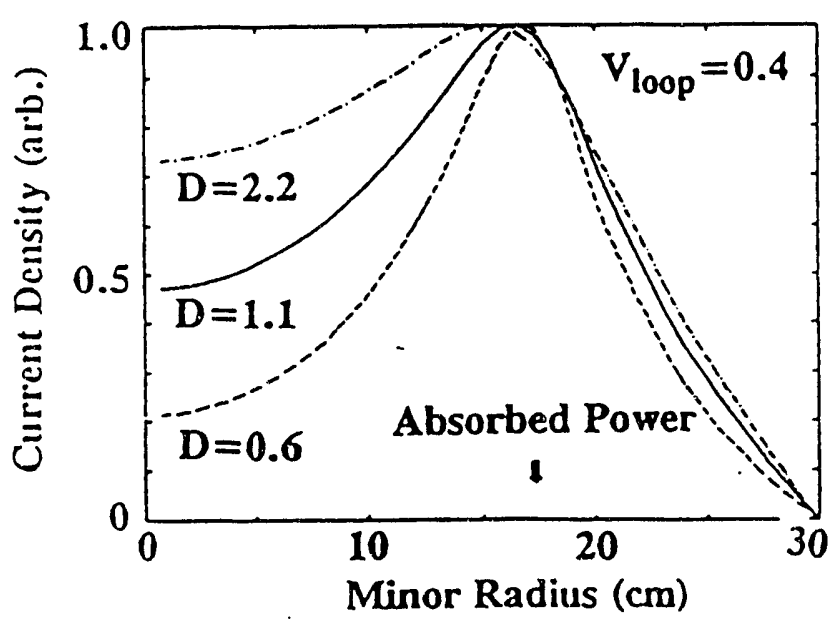

b)

Fig. 5 

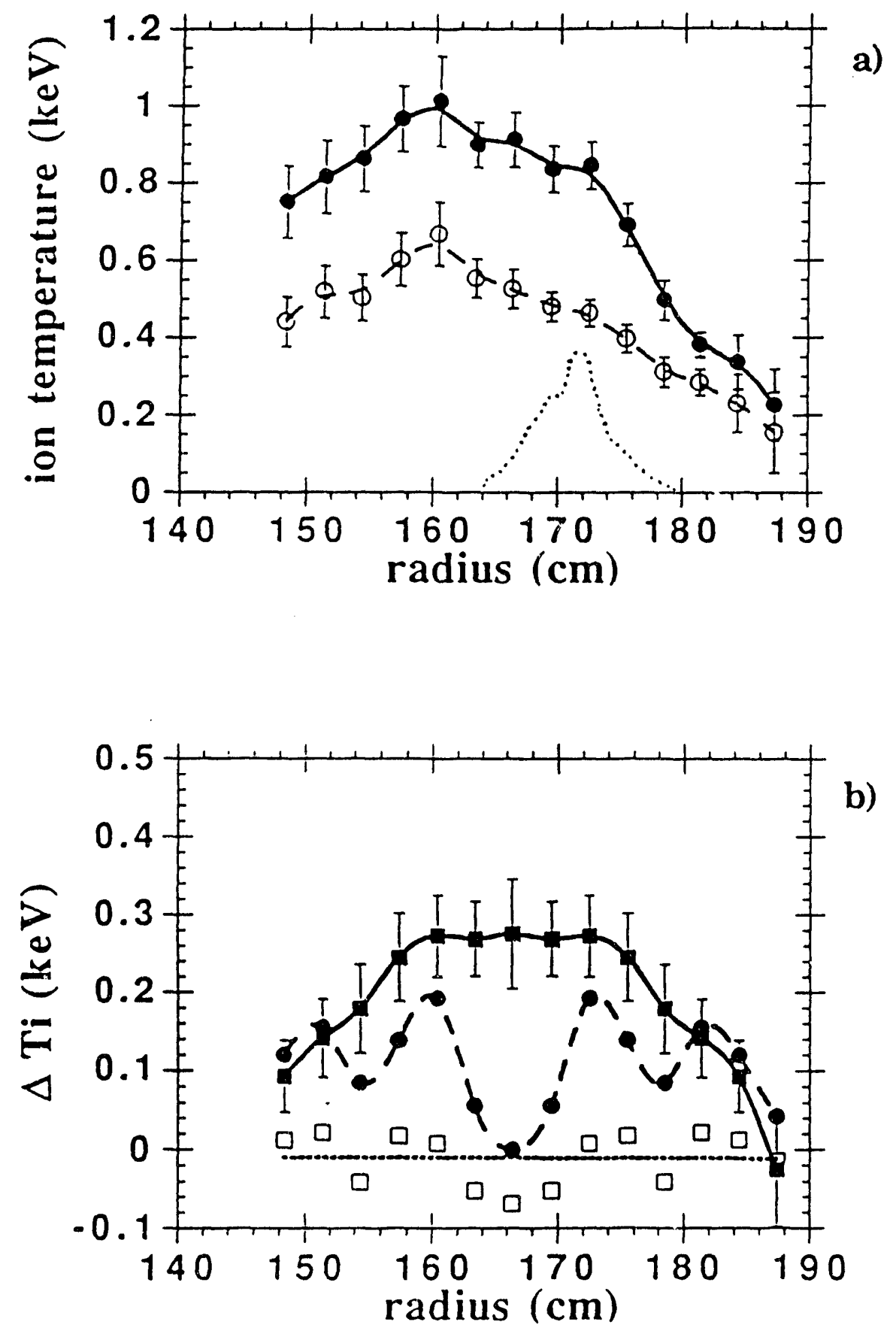

Fig. 6 


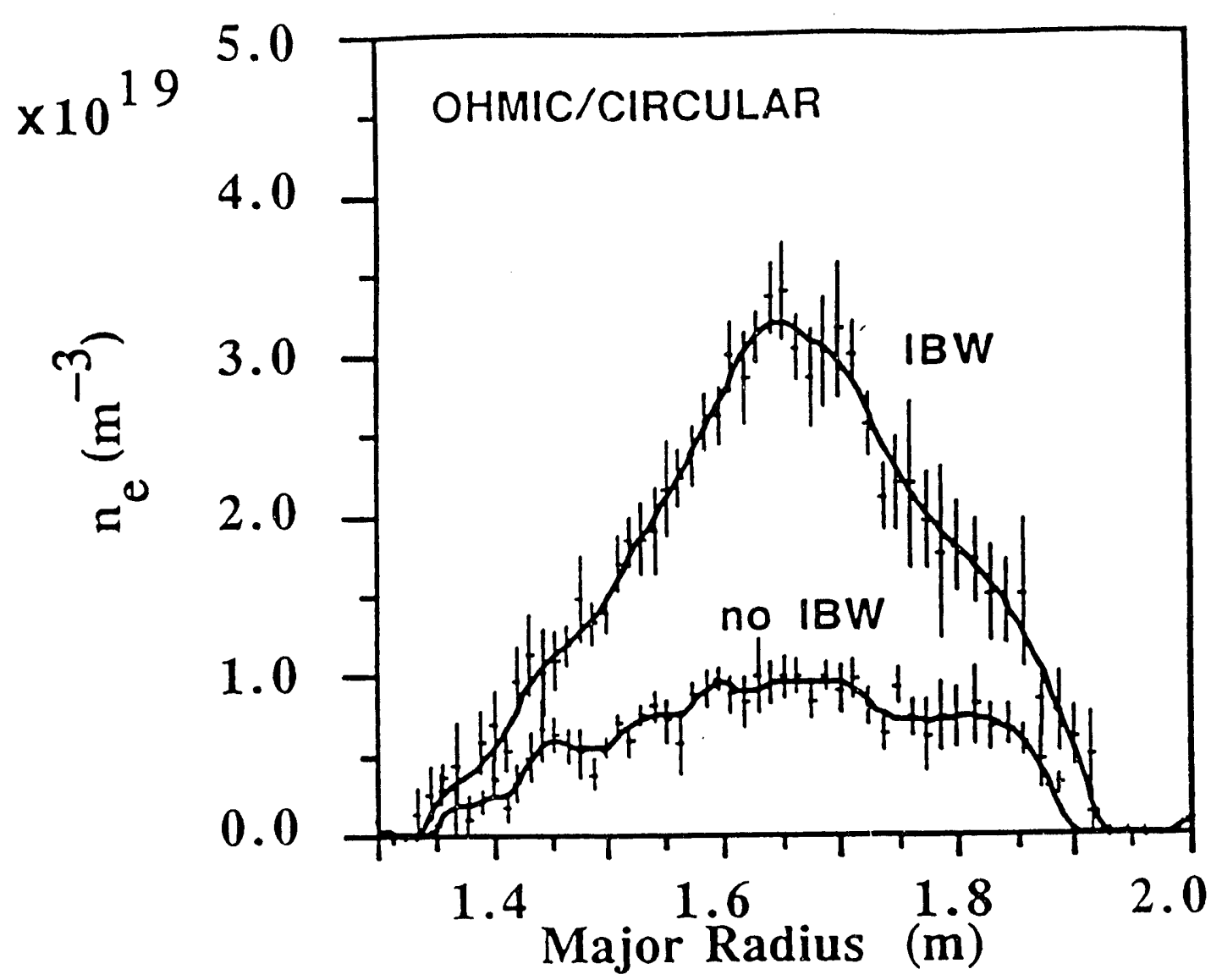

a)

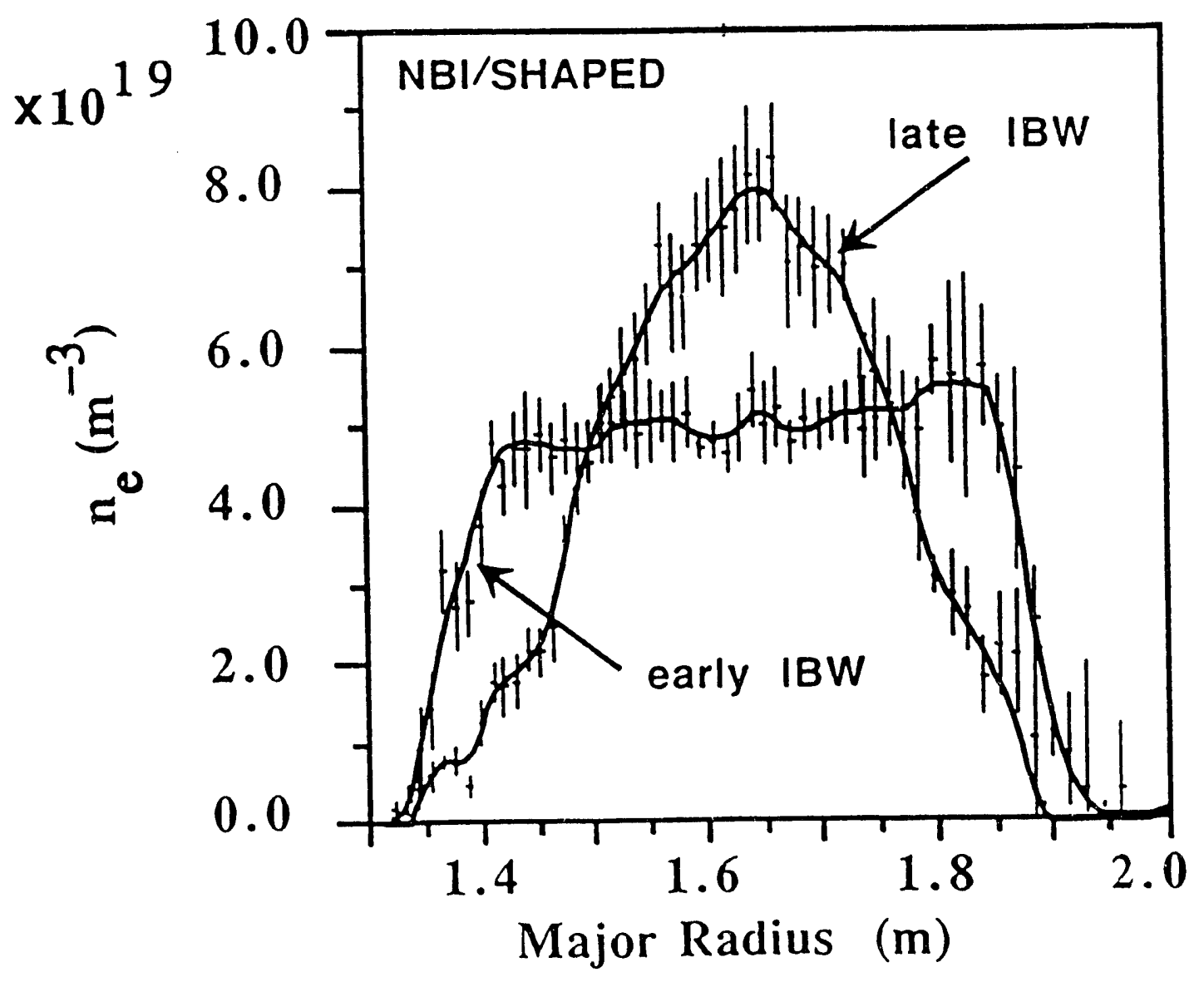

b)

Fig. 7 


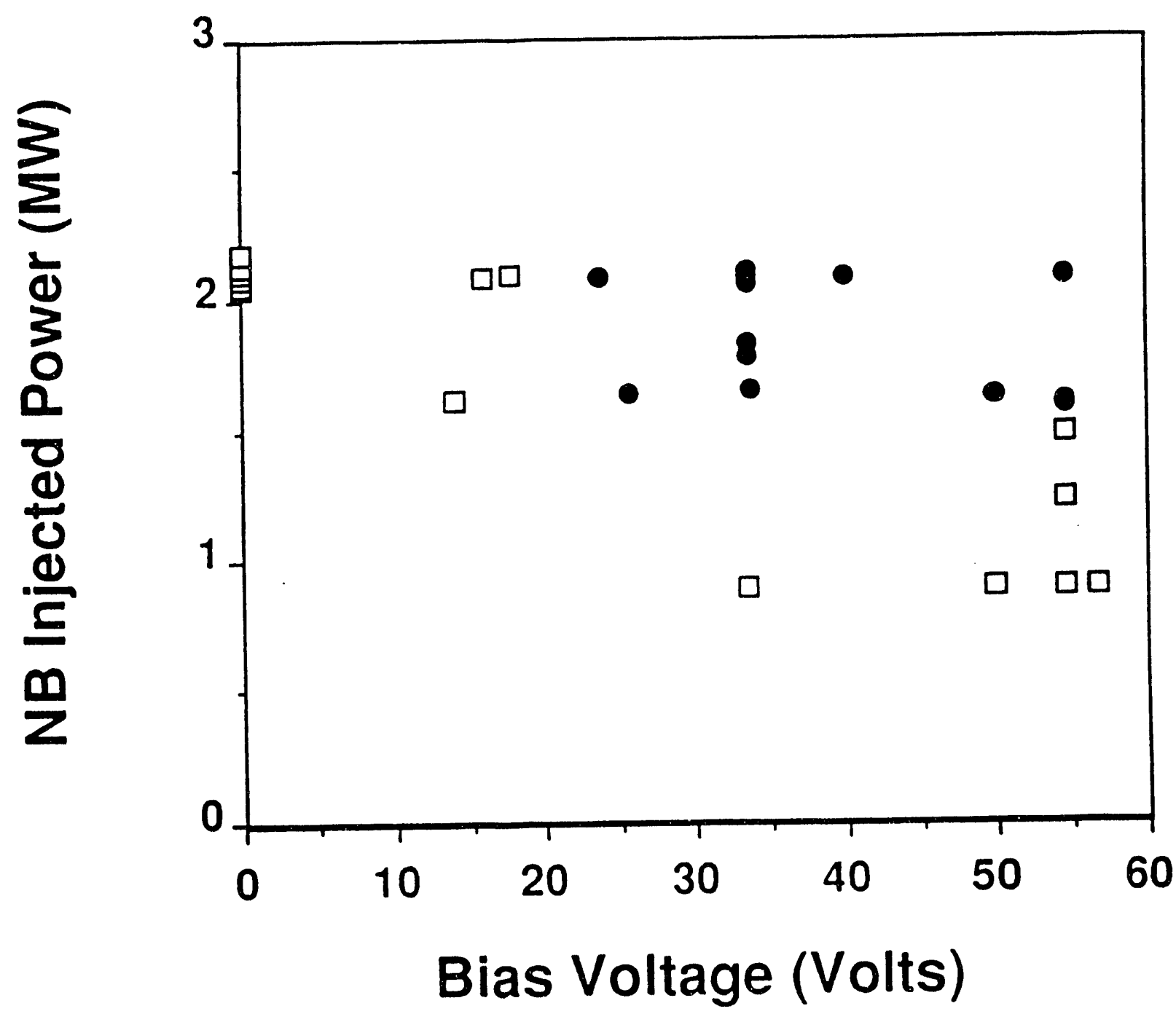

Fig. 8 
Dr. F. Peotoni, Univ. of Wollongong. AUSTRALIA

Prof. M.H. Brennan. Univ. of Syoney, AUSTRALIA

Plasma Aasesszch Lob., Austrdien Nat Univ., AUSTRaLIA

Prof. I.R. Jones, Findors Univ, AUSTRALIA

Prof. F. Cep, Inst for Theoreticel Physics. AUSTRIA

Prof. M. Heindies, Instaue tor Theoretisctio Physik, AUSTRIA

Prot. M. Goosewns, Aetronomisch InstituUt, BELGIUM

Ecob Roydo Mllteirs, bo Phy. Plaemas, BELGIUM

Commiccion-Europeen, DG. XII-Fusion Prog., BELGIUNI

Prof. R. Bouciqus, Rukeuniverituit Gent, BELGIUM

D. P.H. Sakenake, Insturto Fiaica, BRAZIL

Inetivito Neciond Do Poequieas Espacisie-INPE, BRAZIL

Documents Ollios, Abomic Eneroy of Ceneda LId., CAMADA

Or. M.P. Bechyncti, MPB Technologies, Inc., CANADA

Dr. H.M. Skaregard, Univ. of Sackatchowen, CANADA

Prof. J. Teichmem, Univ. of Montreal, CANADA

Prol. S.R. Srcenivaen. Univ. of Cegory, CANADA

Prof. T.W. Johnston, INRS-Energin. CANADA

Dr. R. Botion, Contro cansedien de tusion megnstique, CANADA

D. C.R. Jemes., Univ. of Nberta, CAMAOA

Dr. P. Lukle, Komenaktho Univerezita, CZECHOSLOVAKIA

Tho Librerien, Cumem Laboratory, ENGLAND

Librery, R31, Authertord Appleten Laboratory, ENGLAND

Mrs. S.A. Hubchineon, JET Librey, ENGLAND

D. S.C. Sheme, Univ. of South Pecific, FIJI ISLANDS

P. Munonen, Univ. of Helainid. FINLAND

Prof. M.N. Buasece, Ecolo Potyuchnique., FRANCE

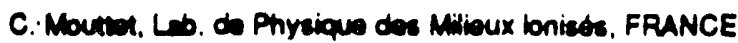

J. Padal CENCADAPACHE - BAI 506, FRANCE

Prot. E. Economou, Univ. of Crewe, GREECE

Ms. C. Rinni, Univ. of loennina, GREECE

D. T. Mud, Academy Bibliogrephic Ser., HONG KONG

Proprint Lbrery. Hungarian Academy of Soi. HUNGAPY

Dr. B. Descupta, Saha inst of Nuctoer Phyeics, INDIA

D. P. Kaw, Inst. for Plaerma Aocearch, INDIA

D. P. Rosenew, leved inst of Technology, ISPAEL.

Librerien, Internationed Conter for Theo Physics, ITALY

Mies C. De Pab, Associaziono EURATOMENEA, ITALY

Dr. G. Groseo, lativio d Fisica ded Plasma, ITALY

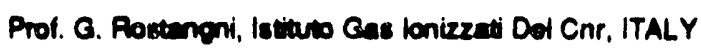

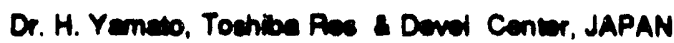

Prof. I. Kewakemi, Hiroshima Univ., LAPAN

Prof. K. Nichikenwa, Hirochima Univ., MAPAN

Director, Jepen Atomic Energy Research inst. JAPAN

Prot. S. Ion, Kyuchu Univ., JAPAN

Pesarech info. Cr., Mationd Inatt. for Fusion Scienco, JAPAN

Prot. S. Tenaka, Kyoto Univ., JAPAN

Librery, Kyow Univ., JAPAN

Prot. N. Inow, Univ. of Tolyo, LAPAN

Secretary, Pleama Secion, Electrowachnical Lab., JAPAN

S. Mori, Techniced Advinot, MAEP, MAPAN

D. O. Mind, Kumanoso hate of Technolooy. JAPAN

J. Hyoon-Sook, Korea Abric Enory Pocearch inst. KOREA

D.I. Chad, The Korea Adv. Inst of Sai. Iech., KOREA

Prot. 8.S. Liby, Univ. of Wrikato, NEW ZEALAND

Int of Pinyices, Chinese naed SA PEOPLE'S REP. OF CHINA

Librery, Inat of Plasma Phycics, PEOPLE'S REP. OF CHINA

Teinghua Univ. Lborery, PEOPLE'S REPUBLIC OF CHINA

2. Li, S.W. Inat Physica, PEOPLE'S REPU日UC OF CHINA

Prol. J.A.C. Cebre, Institus Superior Tecnico, PORTUGAL

Dr. O. Potrus, Al I CUzA Univ., ROMania

Dr. J. do Wivers, Fusion Suctios, AEC, S. AFPICA

Prot. M.A. Hemberg. Univ. of Nated, S. AFFICA

Prot. D.E. Km, Paheno hat. of Sai. \& Tech., SO. KOAEA

Prot. C.I.E.MA.T. Fueion Divicion Library, SPAIN

Dr. L Stenito, Univ. of UMEA, SWEDEN

Librery, Royd inct of Tectnolooy, SWEDEN

Prot. H. Whatmeon, Chalmers Univ. of Tech., SWEDEN

Centere Phys. Des Plaenes. Ecolo Pohyech, SWITZERLAND

Bibliotheak, Inet. Voor Plaserna-fyeica, THE NETHERLANDS

Aest Prot. Dr. S. Cedir, Modds Eeat Tech. Univ., TUAKEY

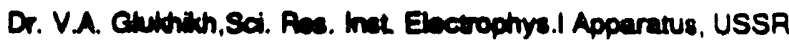

Dr. D.D. Ayutov, Siberien Brench of Acadeny of Sa., USSR

D. G.A. Eiberv, I.V. Kurchalov Inat, USSR

Librerion, The Ukr.SSA Acedemy of Sciences, USSIA

Dr. LM Kowizhnyth, Inat of Cenord Phyaica, USSA

Kemtorectungaanieges GribH, Zentrebibiothex, W. GERMANY

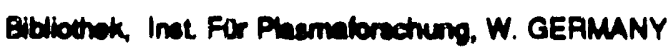

Prof. K. Schindiex, Ruhr-Univerain Bochum, W. GERMANY

Dr. F. Weoner, (ASOEX), Muxplanck-tnetiut, W. GERMANY

Librevien, Max-Planck-Instite, W. CERMANY

Prot. R.K. Janev, Inat of Phycica, rucoslavia 

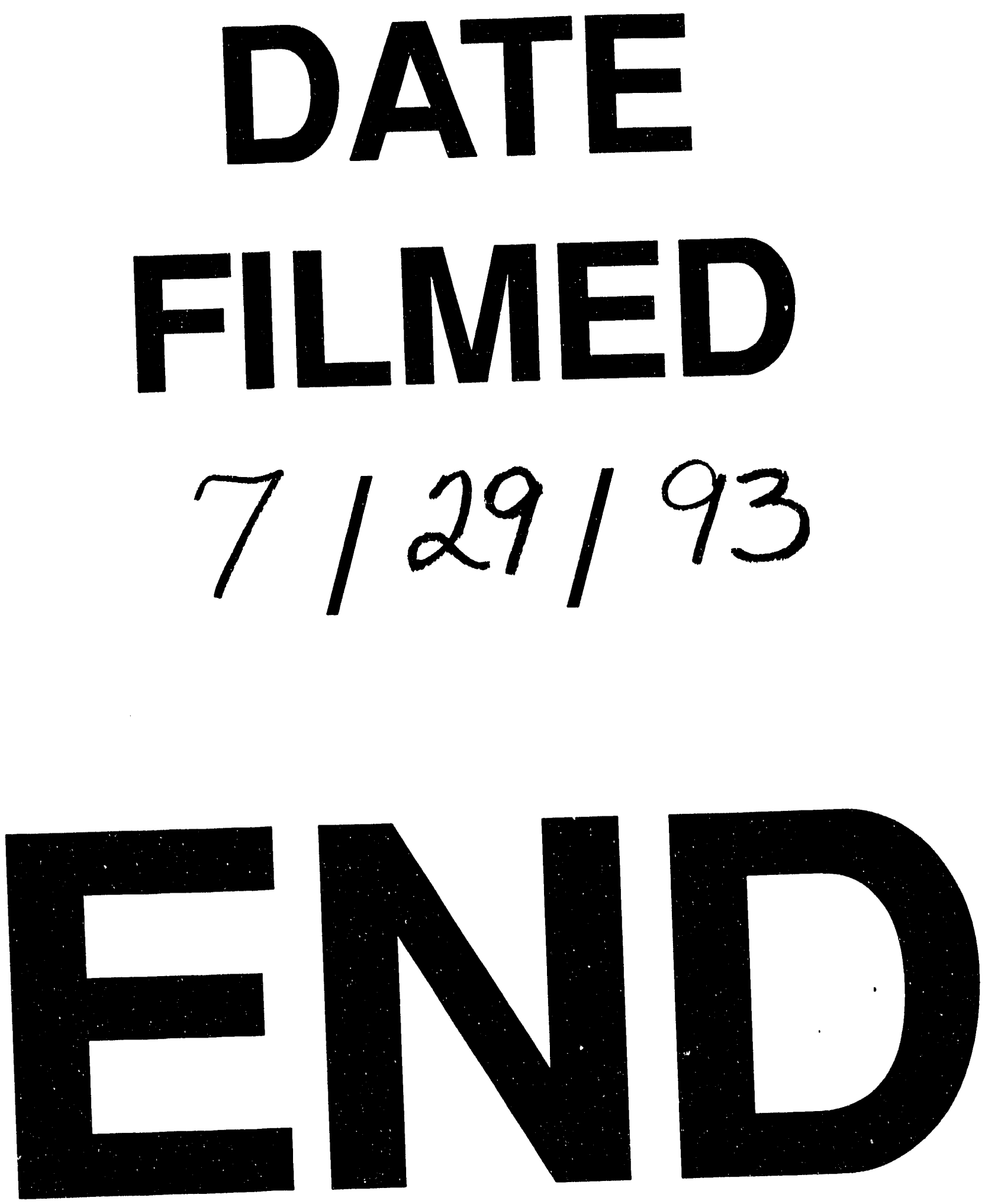
